This is a self-archived - parallel published version of this article in the publication archive of the University of Vaasa. It might differ from the original.

\title{
Digital factory - virtual reality environments for industrial training and maintenance
}

Author(s): Shamsuzzoha, Ahm; Toshev, Rayko; Vu Tuan, Viet; Kankaanpää, Timo; Helo, Petri

Title: Digital factory - virtual reality environments for industrial training and maintenance

Year: $\quad 2019$

Version: Accepted manuscript

Copyright (C)2019 Informa UK Limited, trading as Taylor \& Francis Group. This is an Accepted Manuscript of an article published by Taylor \& Francis in Interactive learning environments on 10 June 2019, available online: http://www.tandfonline.com/10.1080/10494820.2019.1628072.

Please cite the original version:

Shamsuzzoha, A., Toshev, R., Vu Tuan, V., Kankaanpaa, T., \& Helo, P., (2019). Digital factory - virtual reality environments for industrial training and maintenance. Interactive learning environments.

https://doi.org/10.1080/10494820.2019.1628072 


\title{
Digital factory - virtual reality environments for industrial training and maintenance
}

\author{
Ahm Shamsuzzoha ${ }^{1}$, Rayko Toshev ${ }^{1}$, Viet Vu Tuan ${ }^{2}$, Timo Kankaanpaa ${ }^{3}$ and Petri Helo ${ }^{1}$ \\ ${ }^{1}$ School of Technology and Innovations, University of Vaasa, PO Box 700, FI-65101, Finland \\ ${ }^{2}$ Wartsila Oy, Vaasa, Finland \\ ${ }^{3}$ Vaasa University of Applied Sciences, Vaasa, Finland
}

\begin{abstract}
This study evaluates the use of virtual reality (VR) platforms, which is an integrated part of digital factory for industrial training and maintenance system. The digital factory based VR platform provides an intuitive and immersive human-computer interface, which can be an efficient tool for industrial training and maintenance services. The outcomes from this study suggested that use of the VR platform for training and maintenance of complex industrial tasks should be encouraged and use of the VR platform for that purpose should be further evaluated. This paper highlighted the generic concept of the application of virtual reality technique within digital factory to industrial maintenance and to build a low-cost VR application for training and maintenance system. An application case on virtual reality technique in a power plant operations and maintenance is demonstrated within the scope of this research. Overall research implications on virtual reality concept in industrial applications are concluded with future research directions.
\end{abstract}

Keywords: Digital factory, virtual reality, human-machine interface, virtual operations and maintenance, industrial application, case example.

\section{Introduction:}

The concept of digital factory can be defined as the interactive 3D environment, where digital technologies are used for modeling, communications and to operate the manufacturing process (Kuhn, 2006). This kind of environment allows managers to configure, design, screen and control of a production system. Among other technologies, simulation is a key technology within this concept, where various types of simulation, such as discrete event or 3D-motion simulation is used to virtual models to enhance the operative production planning and control as an integrated process from the top level to the factory floor control. In addition, the integration between simulation and optimization techniques offer advanced approaches for planning and improving the product development and production planning processes.

The interactive 3D virtual environment in the form of digital factory provide an enabling circumstances for innovation and evolution in manufacturing system, training, maintenance and repair operations of industrial plants (El-Chaar et al., 2011). In fact, technique 3D virtual-operation facilities promotes a new approach to technical documentation and assistance, where the user can be easily guided even through the most complex and critical operations simulation of products processes and manufacturing. This technique mainly introduces the main characteristics of the Virtual Reality Environments in the contexts of manufacturing maintenance and training-centered. 
This VR environment integrates the in 3D modeling, 3D animation and simulation, and humanmachine interface technologies (El-Chaar et al., 2011).

Virtual Reality (VR), which is one of the technology used in digital factory can be defined as an environment that is created by the use of computer technology to develop effect of an interactive 3D world in which objects have a sense of spatial presence (Bryson, 1994). It is generally considered as a natural extension to 3D computer graphics. This technique has matured enough until today to guarantee effective industrial applications. The virtual reality technique with up-todate software systems supports various industrial applications such as design, engineering, manufacturing, operations and maintenance. The integration between virtual reality and industrial operations provides necessary support to develop cost efficient production system with sophisticated maintenance management. This is regarded as promising training platform for relatively complex and high demanding industrial operations and maintenance tasks.

The main difference between VR and traditional 3D computer graphics is that it works with things instead of pictures of things (Popovski et al., 2014). In any virtual environment, interaction is an essential characteristic. In general, the interaction is an important component of virtual environments and the interaction between the virtual environments and the users is very complex. In this environment, the users must be able to navigate through three-dimensional space, where the users manipulate with virtual objects.

VR has been applied widely in real-world, non-trivial problems. There are several commercial 3D engineering tools for digital mock-up but many of them lack still lack an intuitive direct manipulation of the digital mock-up by human (Gomes de Sa and Zachmann, 1999). Therefore, available commercial 3D engineering tools are inherently inferior to VR for specific applications. VR technique as a tool has already begun to routinely use in different business domains. Over the years, researchers have proposed various approaches to maintenance activities. One of them is considered 'virtual reality' as the way to provide industrial maintenance (Gomes de Sa and Zachmann, 1999, Nomura and Sawada, 1999; Sacco et al., 2011; Tolio et al., 2013).

VR approach employs a computer-generated environment to simulate interaction with the real system. With VR system different technologies can be integrated with the objective to allow users to interact with the virtual scenario in a multi-sensory manner. The VR system provides a range of benefits compares to traditional learning and training (Choi et al., 2015). It provides training under learning-by-doing approach (Stork et al., 2012). It is widely used in styling and design reviews in the conceptual phase of product development, but not been elaborately and efficiently used in products operations and maintenances. Based on the above circumstances, the overall objectives of this proposed research study can be outlined as:

(1) To introduce relevant supporting technologies within digital factory that can be successfully implemented to real-time industrial training and maintenance needs

(2) To promote virtual reality environment within digital factory for industrial training and maintenance activities for mutual benefits

(3) To develop essential guidelines to assist in the maintenance activities through virtual environment

The rest of the paper is organized as follows: Section 2 highlights relevant literatures on digital factory and virtual reality environment and its implementations in various business sectors, while, Section 3 outlines the application of VR in training, operations and maintenance. Section 4 presents a framework usable to establish the virtual maintenance environment. Virtual prototype to enhance VR maintenance environment is outlined in Section 5, whereas, necessary technologies tools and tools to create VR operational environment is outlined in Section 6. Basic requirements 
and technical details of the case example is highlighted in Section 7. A case example with the objective to demonstrate the VR industrial maintenance is stated in Section 8, while, empirical and managerial implications are presented in Section 9. Overall conclusions with future research directions are presented in Section 10.

\section{Theoretical framework}

The concept of digital factory and manufacturing has been considered, over the last decade, as a highly promising set of technologies to support customized production with reduced lead-time and cost. This factory is considered as a comprehensive approach of network of digital models, methods and tools including virtual reality and 3D simulation (Sacco et al., 2007). It provides the need for product customization, enhanced product quality, and faster response to the market (Chryssolouris et al., 2009). Within the scope of this paper, the evolution of information technology systems in manufacturing is described through outlining their characteristics and functionalities can be successfully implemented in manufacturing. In order to form the digital factory and manufacturing environments, these technologies are used through integrating to the computer-aided design, engineering, process planning and manufacturing, simulation and virtual reality, automation, manufacturing resource planning, enterprise resource planning, logistics, supply chain management, and e-commerce systems.

Within a digital factory, virtualized environments supports collaborative design, planning, production, maintenance and training. Digital factory platform supports the high rate of innovations by introducing high-tech with fast and efficient approaches for information and knowledge transfer, especially in the area of service and maintenance activities. This platform helps to improve the overall service quality in manufacturing and reduce the costs associated with maintenance operations and training. The developed tool for virtual reality (VR) based maintenance and training supports the creation of VR-based workflows and their execution within a collaborative environment. VR based maintenance work also provides an efficient remote maintenance service using the virtual reality techniques. This kind of tool supports maintenance work of machines in an optimized, immersive and interactive way (Souza et al., 2006).

\subsection{Virtual reality business environment: fundamental issues}

The concept of VR is a systematic, three-dimensional, interactive environment usually created by a computer. This environment provides a unique path to enhance the visualization of complex 3 -dimensional objects and offers more interactive and spatial ability. In this research study, several available VR systems for industrial applications have been reviewed. Akiyoshi et al. (1995) developed a VR-based power equipment maintenance system, while Kashiwa et al. (1995) highlighted an immersive VR system to conduct training for maintenance work. Li et al. (2003) proposed a desktop-based VR system to use for maintenance training. More applications are highlighted in the following sub-sections.

From the literature review, it is noticed that current researches on VR-enabled maintenance works are mainly coupled with immersive or augmented VR technology, which is higher in cost. Due to higher cost such technology is not practical. In addition, with respect to ergonomics issues most VR devices is still a problem to the user. Therefore, in the field of VR, many users prefer a desktop-based VR system, which is cheaper and portable (Li et al., 2003). Furthermore, desktopbased VR system provides collective visualization that enabled the knowledge and information 
sharing during industrial training and maintenance process. It offers not only industrial maintenance and training but it also provides necessary learning process as well.

The advancement of computer technology contributes to movement from mass production to the production of a variety of goods in small quantities. Today's customers' needs are mostly on one-of-a-kind products, which can easily accommodate an individual customer's needs. To fulfill such need, VR technique can be employed successfully (Nomura and Sawada, 1999; Tolio et al., 2013). The application of virtual reality technique can be helpful to simulate and improve product development processes before they are actually carried out in real-life manufacturing environment (Lawson et al., 2016). This technique ensures the product development activities such as design, planning, machining, etc., is performed well advance without the need for subsequent modifications and rework (Mujber et al., 2004; Pappas et al., 2006; Galambos et al., 2015).

\subsection{Application of VR in manufacturing industries}

Research on the application of VR is a strong and fast growing area. It is well known technology and is currently being investigated for practical use in various industrial applications. The application of VR in manufacturing processes as well as product and process development can lead to shorter developmental time with reduced cost and improved quality (Canetta et al., 2011; Yang et al., 2015). The objective of VR is to create a system that is as perfect as the real world, if not better and more efficient. The concept of virtual manufacturing is evolved from VR, which has greatly changed traditional manufacturing industries (Choi et al., 2015). VR technique enables customers to examine a design and make changes at the initial phase of the product development process. In addition to design, prototyping, and layout planning, VR technique applies in teleoperations, operator training and entertainment (Sacco et al., 2011; Frampton, 1995). This technology is offers a cost-effective means of supporting the development of human skills and training in various fields from automotive engineering to defense, surgery to education, retail, petrochemical exploration, and heritage to micro-robotics.

Virtual reality successfully applied in manufacturing industry in the form of virtual manufacturing. This virtual manufacturing is an emerging technology, which mimics the real life manufacturing operations and processes into simulations and artificial intelligence (Lee et al., 2001). Such virtual manufacturing environment is a knowledge and information-based technique, which is used successfully to reduce manufacturing costs and time-to-market. The VR experience is proposed towards e-manufacturing and its application (Cheng and Bateman, 2008). Such emanufacturing is promising globally and its impact is increasing on modern manufacturing industry and practices.

\subsection{Application of VR in various sectors}

Applications of VR in industrial environment can be found in literature from past several decades. For instance, VR is successfully applied in such as automotive industries (Zimmermann et al., 1999; Zimmermann, 2008; Liang, 2009; Stork et al., 2012), video game (Lecuyer et al., 2008; McMahan et al., 2012; Maeve et al., 2016), health science (Levinson et al, 2007; Alamri et al., 2008; Llorens et al., 2015), education and training (Buriol et al., 2009; Gutierrez et al., 2012; Yuviler-Gavish et al., 2013; Gavish et al., 2015), etc. Although, in literature vast amount of researches have been found on the applications of VR in multi-directional fields, however, very limited amount of works are found in the operational maintenance and training. This research gap 
is mainly focused within the scope of this study. The development of VR-based maintenance and training can be used cheaply and efficiently in industrial applications.

The application of VR is tested in construction industries, where the researchers review its potential use in improving design and construction processes (Amir et al., 2017). In entertainment industry, VR is already being applied. Home-based virtual reality games are growing dramatically, despite a lack of computing power and high cost of most virtual reality equipment. However, advanced VR is set to invade the home entertainment in the recent years that comes over the Internet to promote human interaction over wide distances. This VR-based entertainment is immersed in a 3D world, interacting with other participants and can become a real, role-playing event. It is promoting marketing of game industry through interactive user interface (Ribaupierre et al., 2014; Hu et al., 2016). In case of marketing and sales, VR is extensively used nowadays by the companies to experience their products with the potential customers and to understand them better (Gorski et al., 2015; Zawadzki and Zywicki, 2016). It is expecting that in the near future, VR will be used to design, develop, and test products with much greater customer involvement. In that case, any company will be able to create its products, gain customer feedback and modify the products in rapid pace and lower cost if needed. In this way, the product prototype can directly be tested before creating the physical product. This kind of electronic prototype may also be used to develop true customized products that are portrayed in virtual reality, customized by an individual customer, which can be transferred electronically to a production facility.

The application of virtual reality in medical science is considering promising recently. It is just starting to be applied in developing medicine and medical research. It is extensively using in biochemical engineering, where the medicines are tested through docking of molecules using visual and auditory displays. VR is also being applied to practice aiming X-rays before cancer treatments. Different medicine companies are creating virtual bodies, a kind of 'body electronic' to enhance medical training. Through VR technology, medical students are able to study anatomy by dissecting virtual cadavers-a much more cost effective and efficient way of studying the human body. Through interactive virtual surgery, medical students and surgeons are able to practice before attempting a new procedure. The students can be able to practice an operation for a specific patient, whose unique body characteristics have been scanned into the computer.

VR also offers greater attention towards tourism industry, where it helps necessary planning, marketing, education, accessibility and heritage preservation in the tourism areas (Guttentag, 2010; Gibson and O'Rawe, 2018). This technology particularly valuable to create virtual experiences that tourists may accept as substitute's for real visitation to threatened sites. It enables astrology students to visit a range of virtual galaxies to study their properties. Tourists would be able to visit different historical events and perhaps even participate in the action with historical figures through the application of VR technology. Table 1 displays different application areas of virtual reality environment.

\section{Table 1}

Application of VR in different domains.

\begin{tabular}{|l|l|l|}
\hline Application area & \multicolumn{1}{|c|}{ Contribution } & \multicolumn{1}{c|}{ Author } \\
\hline Rehabilitation & $\begin{array}{l}\text { Rehabilitation assessment, treatment, and } \\
\text { research. }\end{array}$ & $\begin{array}{l}\text { Schultheis and Rizzo } \\
(2001), \text { Rizzo and Kim } \\
\text { (2005), Standen and Brown }\end{array}$ \\
\hline
\end{tabular}




\begin{tabular}{|c|c|c|}
\hline & & $\begin{array}{l}\text { (2005), Gamito et al. } \\
\text { (2017) }\end{array}$ \\
\hline $\begin{array}{l}\text { Education and } \\
\text { training }\end{array}$ & Real-world training, VR training. & $\begin{array}{l}\text { Kozak et al. (1993), } \\
\text { Kaufmann et al. (2000), } \\
\text { Ganier et al. (2014), Chen } \\
\text { (2016), Martin-SanJose et } \\
\text { al., 2017); Wang et al. } \\
(2018)\end{array}$ \\
\hline Verification & Assembly verification and maintenance. & $\begin{array}{l}\text { Gomes de sa and } \\
\text { Zachmann (1999), Guo et } \\
\text { al. (2018) }\end{array}$ \\
\hline $\begin{array}{l}\text { Industrial } \\
\text { maintenance and } \\
\text { assembly }\end{array}$ & $\begin{array}{l}\text { Industrial maintenance and assembly tasks } \\
\text { training. }\end{array}$ & $\begin{array}{l}\text { El-Chaar et al. (2011), } \\
\text { Gavish et al. (2015) }\end{array}$ \\
\hline $\begin{array}{l}\text { Manufacturing } \\
\text { simulation }\end{array}$ & $\begin{array}{l}\text { Rapid prototyping, manufacturing, } \\
\text { scientific visualization, engineering and } \\
\text { education. }\end{array}$ & $\begin{array}{l}\text { Mujiber et al. (2004), Seth } \\
\text { et al. (2015) }\end{array}$ \\
\hline Neuropsychology & $\begin{array}{l}\text { Development of innovative } \\
\text { neuropsychological assessment and } \\
\text { rehabilitation tools. }\end{array}$ & $\begin{array}{l}\text { Rizzo et al. (2004), Bohil et } \\
\text { al. (2011), Lecavalier et al. } \\
\text { (2018) }\end{array}$ \\
\hline Human factors & $\begin{array}{l}\text { Support to human-factors issues, health } \\
\text { and safety issues and the social impact of } \\
\text { the technology. }\end{array}$ & $\begin{array}{l}\text { Stanney et al. (1998), } \\
\text { Lopez et al. (2017) }\end{array}$ \\
\hline $\begin{array}{l}\text { Social } \\
\text { skills/cognition } \\
\text { training for } \\
\text { autism }\end{array}$ & $\begin{array}{l}\text { Enhancing social skills, social cognition, } \\
\text { and social functioning of adults with } \\
\text { autism. }\end{array}$ & $\begin{array}{l}\text { Parsons and Mitchell } \\
\text { (2002), Kandalaft et al. } \\
\text { (2013) }\end{array}$ \\
\hline Tourism industry & $\begin{array}{l}\text { Creation of virtual experiences so that } \\
\text { potential tourists may accept as substitutes } \\
\text { for real visitation to tourist sites. }\end{array}$ & $\begin{array}{l}\text { Guttentag (2010), Bruno et } \\
\text { al. (2010), Tussyadiah et al. } \\
\text { (2018) }\end{array}$ \\
\hline $\begin{array}{l}\text { Building and } \\
\text { construction }\end{array}$ & $\begin{array}{l}\text { Development of interactive applications to } \\
\text { evaluate the construction work, monitoring } \\
\text { and visualization of details of the form of } \\
\text { every component of each construction. }\end{array}$ & $\begin{array}{l}\text { Goulding et al. (2012), Chi } \\
\text { et al. (2013), Sampaio and } \\
\text { Martins (2014) }\end{array}$ \\
\hline Games industry & $\begin{array}{l}\text { Serious game provides a mental contest, } \\
\text { played with a computer to support } \\
\text { government or corporate training, } \\
\text { education, health, public policy, and } \\
\text { strategic communication. }\end{array}$ & $\begin{array}{l}\text { (Zyda (2005), Lange et al. } \\
\text { (2012), Gamito et al. } \\
\text { (2017), Zhang et al. (2018) }\end{array}$ \\
\hline Health care & $\begin{array}{l}\text { Provides high potential of enhancing the } \\
\text { training of health-care professionals. Such } \\
\text { training can provide a rich, interactive, } \\
\text { engaging educational context, thus } \\
\text { supporting experiential learning-by-doing. }\end{array}$ & $\begin{array}{l}\text { Mantovani et al. (2004), } \\
\text { Freeman et al. (2017), Ho } \\
\text { et al. (2018) }\end{array}$ \\
\hline
\end{tabular}

\section{Virtual reality to enhance training, operations and maintenance}


The VR is successfully used in virtual training, where a virtual plant operator uses a realistic, data-based 3D environment. In this training environment, virtual reality glasses are used to train plant personnel to handle emergencies. Human workers are equipped with virtual reality glasses that can put the necessary manufacturing information in their field of vision. The glasses uses virtual reality to highlight the location, where each component of a machine or equipment should be maintained. Through such virtual world, operators can learn to interact with machines and equipment by clicking on a cyber-representation. With this virtual world, sometimes called 'digital twin', manufacturers can improve their after sales services, and generate insights that can be used to optimize the design of future machines or equipment.

VR is extensively using in education and training. Nowadays, students are able to learn through studying in virtual worlds. It can be successfully used in teaching adults. Through VR technology, trainees are allowed to walk through a virtual factory and learn about health hazards-a more engaging experience than reading a manual or attending a lecture. It enables students to conduct experiments without risking an operation. In engineering courses, the students are able to use virtual reality simulations to create and test prototypes. On average, each of every three giant automakers uses some form of virtual reality to test its new models. In case of aerospace industry, each of the aircraft is to be designed and tested using virtual-reality technology for its performance. Such virtual designing and testing save money in prototyping and avoid cost overruns. In future, most of the engineering sectors will implement virtual-reality prototypes with the objective to share, evaluate, and modify product designs, which can be an input from both co-workers and customers.

Virtual operations and maintenance requires the integration of multiple domains and it is important to synchronize related technologies to enable industrial applications of virtual maintenance. It is envisioned that the VR system will converge as new maintenance system in virtual manufacturing environment. This virtual environment will allow the maintenance engineer to virtually maintain the product to make it operable. The virtual maintenance system offers relevant training and learning to the maintenance engineer with an easy and flexible way. This paper describes work related to VR for industrial maintenance, the design of a virtual maintenance environment and preliminary results from the use of this environment. For this research work, VR is defined as the use of computer-generated virtual environments and associated hardware and software systems to provide the user with the illusion of physical presence within that environment.

VR technologies that allows for virtual operations and maintenance are not yet fully utilized by industry. Although VR is growing rapidly but it is not completely understood in regards to its applications within manufacturing industries. It is considered as a key component of virtual manufacturing, where the use of computer tools assist with maintenance-related engineering solutions by analysis, visualization and presentation of activities without physical realization of the supporting processes (Gomes de Sa and Zachmann, 1999). Virtual maintenance (VM) is assisted by several technologies such as advanced visualization, simulation, decision theory, maintenance procedures and maintenance equipment development.

The use of virtual maintenance system using virtual reality technologies has been found to provide a range of advantages over the traditional training and maintenance systems (Gavish et al., 2015). It offers necessary maintenance training under the learning-by-doing approach, which is not possible in real-life environment due to limitations such as cost, time, safety, etc. In addition, virtual maintenance system facilitates the training process through visual, auditory or haptic cues 
and allows simulating the task in a flexible way to adapt the users' requirements and training objectives (Gosselin et al., 2010).

Virtual maintenance technologies cross multiple domains and technical structure. These technologies are needed to be synchronized to efficiently support the virtual maintenance.

It is important that designers thoroughly analyzed the manufacturability and maintainability of the new products during early design phase in order to avoid high developmental cost. This design realization supports the user to have high confidence during virtual maintenance system. As the virtual maintenance is developed, the exploitation of the knowledge and information is required to mapping VR and CAD descriptions to maintenance plans. This abstract maintenance model contains sufficient maintenance information such as component sequence, feature datum's, maintenance trajectories, component orientation and tolerance data to support decisions in maintenance process selection and enabling more detailed process definition.

\section{Framework for virtual maintenance environment}

The framework necessary to create virtual maintenance environment can be outlined as in Figure 1. From Figure 1, it is noticed that the framework is consisted of five layers namely, database layer, product data model and management layer, resource and maintenance layer, virtual reality system layer and monitoring and evaluation layer. Each layer contains its own significance and characteristics. 


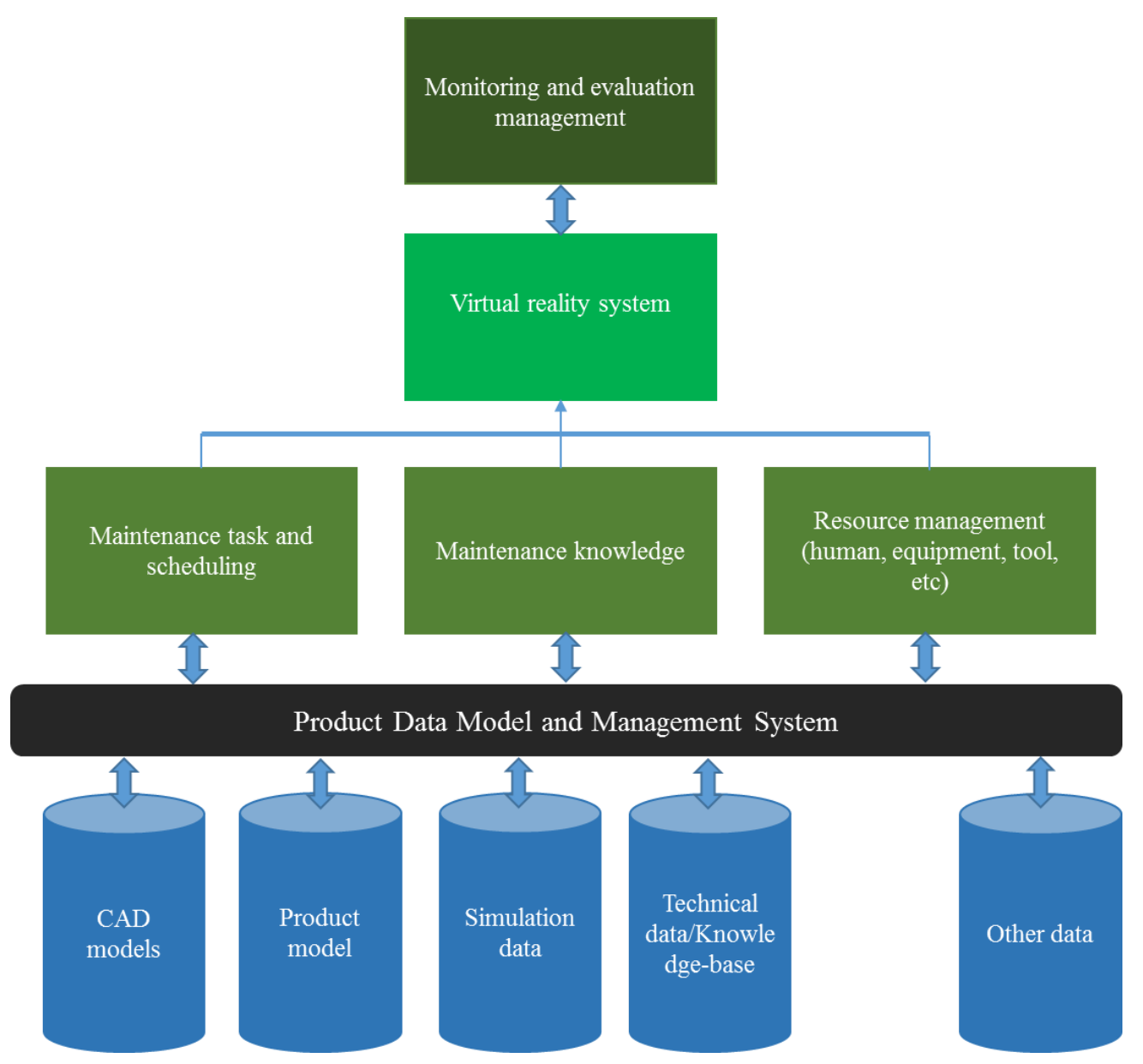

Fig. 1. Framework for virtual maintenance environment (adapted from Gomes and Zachmann, 1999).

Database layer consists of various database as necessary to execute virtual maintenance environment. This layer may contains critical databases like CAD model, product model, simulation data, technical data/knowledge-base and other relevant data. Each of the data model has its own contents and significance. For instance, CAD model contains detailed information related to a design of a product including dimensions, 2D or 3D features, etc.

In the product data model and management layer, all the databases are stored and retrieved according to necessary. All such data can be converted, reduced and prepared for use in VR maintenance system. This data as stored at this layer also maintains administrative data together with other relevant data.

In the third layer, relevant information on maintenance activities is stored. At this layer three different modules namely maintenance task and scheduling, maintenance knowledge and resource management are presented. This layer maintains the repair and maintenance activities of the virtual maintenance environment. It maintains the relevant schedule for maintenance tasks, store maintenance knowledge and arrange necessary resources (human, tools, equipment, etc.) to perform repair and maintenance tasks efficiently.

The fourth layer known as virtual reality system executes the basic virtual reality system, which is considered as the backbone of virtual maintenance tasks. At this layer, necessary engineering 
model of the intended product including geometry, physics and quantitative or qualitative data from the real product. Through this layer, the user would be able to virtually walk through the operating system and be able to response any changes in the design, operation or any other necessary modification of the product.

Final layer is responsible to overall monitoring and evaluation of the virtual maintenance environment. From this layer the progress of maintenance work along with its bottlenecks or difficulties are monitored. In case of any abnormalities, this layer interacts with virtual reality system to overcome the associated problems.

The framework as highlighted here can be useful to form and operate any format of maintenance activities executed virtually. This framework supports manufacturing companies through bridging the communication gap among operational activities. It integrates the complete data pipeline from the CAD systems to the VR system for necessary maintenance activities. Furthermore, this framework carry over necessary data from the product data model and management system.

\section{Virtual prototyping to enhance VR maintenance environment}

In order to promote VR maintenance environment it is essential to develop a prototype. By creating the prototype of the product or process, it is possible to reduce the virtual maintenance work well ahead. However, building the prototype is often very time consuming and expensive as well. Moreover, prototypes do not always offer enough material and dynamic functionality for testing and validation process. The fundamental objective of virtual prototyping is to replace a product or process by using the CAD data of the product or process in combination with available virtual reality tools. This virtual prototype represents at least to some extend the physical prototype.

The virtual prototype offers added benefits to companies. It provides a simulated product or process that can be quickly reproduced and easily modified according to the need. In general, by using simulation systems the designs of products or processes are evaluated. Nevertheless, physical prototyping or mock-ups are still applied in most of the cases. In case of virtual prototyping, virtual reality technique is used to present the digital data realistically and manipulate it intuitively. The main functional requirements of virtual prototyping are to provide a 3D virtual maintenance environment. The overall schematic of a VR-based maintenance environment is displayed in Figure 2.

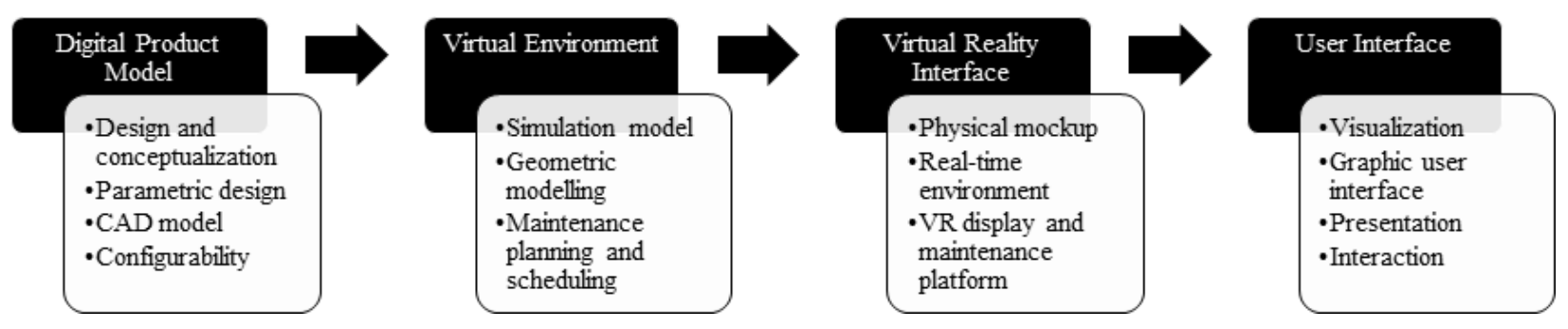

Fig. 2. Schematic diagram of a VR-based maintenance environment.

From Figure 2, it is noticed that VR-based maintenance environment consisted of four phases namely, digital product model, virtual environment, virtual reality interface and user interface. Each of the phases contains its tasks. For instance, digital product model contains tasks as design and conceptualization, parametric design, CAD model and configurability, whereas, virtual 
environment phase contains simulation model, geometric modelling, maintenance planning and scheduling tasks. Similarly, virtual reality interface consisted of tasks as physical mockup, realtime environment, VR display and maintenance platform, while user interface phase contains of visualization, graphic user interface, presentation and interaction tasks.

\section{Creation of virtual reality operational environment - technologies and tools}

Before addressing the virtual reality operational environment, it is better to define it properly. The VR operational environment can be defined as a system, which is mainly created to introduce a specific technical scenario of an industrial facility. To enable smoother $3 \mathrm{D}$ virtual reality operational environment there needs to integrate various technologies and tools. The required technologies and tools should be compatible with each other in order to develop a seamless VR working environment. Both software and hardware systems are combined to create such VR environment, which allow the designer to be immersed in the environment. This system offers the operational engineer with high quality, stereoscopic graphics through using a head-mounted display.

This necessary movement of the head-mounted display (Figure 1) is monitored and controlled by electromagnetic or camera based positioning devices that automatically allow the user to look around. Different movements of the head are monitored and tracked by the hands of the user by additional positing devices. These movements are used to create and manipulate operational scenarios in the virtual environment. In order to monitor the movement of the fingers and wrist, the user uses an instrumented glove. The operational personnel use such virtual working environment to select optimal operational sequencing, evaluate required tolerances, create operational plans and results visualization.

In order to design and develop VR environment, it is essential to integrate multiple domains and synchronize them with related technologies. Such integration makes the VR application more effective and efficient in general. The VR operational environment allows the technicians/engineers to pursue operational activities virtually. This virtual operational system supports relevant training instruction with a reliable and easy way. This environment provides realtime simulation and interaction with a virtual $3 \mathrm{D}$ world.

The application of VR environment requires technologies such as Unreal Engine 4, HTC Vive, HTC Vive Headset, HTC Vive Controllers, HTC Vive Base station, Vive Tracker, etc., (VIVE, 2018). The Unreal Engine 4 is used as the main software to create the virtual environment. This environment is required to simulate virtual industrial operations. The HTC Vive is a virtual reality headset that is designed and developed by HTC and Valve Corporation. It offers 'room scale' tracking technology that supports the user to move in 3D virtual space. The HTC Vive consists of one VR headset, two controllers and lighthouse base stations (Figure 3), which are required parts to create and operate VR environment. 


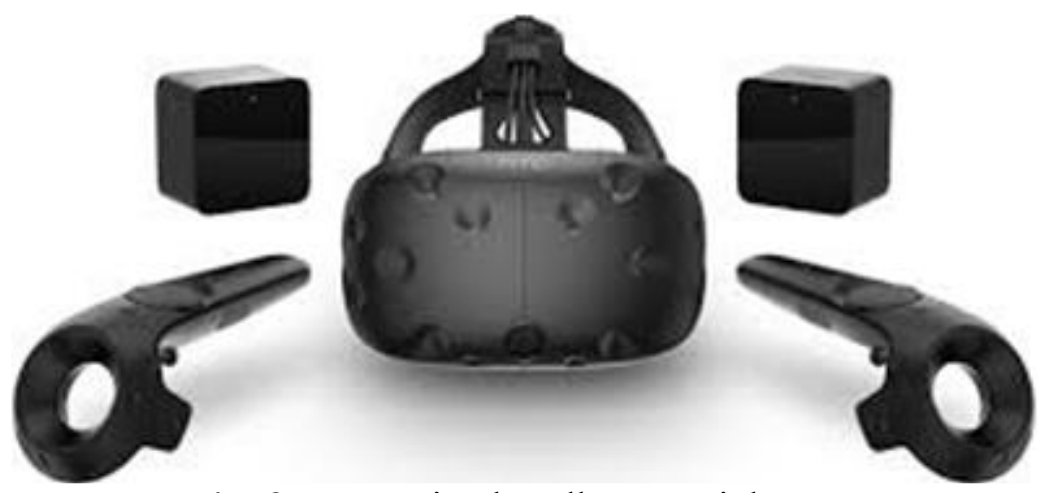

Fig. 3. HTC Vive bundle essential parts.

The HTC Vive headset tracks the head position through a gyro sensor, an accelerometer and a laser position sensor. It uses two screens, one per eye and includes a front-facing camera that allows the user to observe their surroundings. The HTC Vive controllers are considered as the hands of VR that let the user wirelessly interact with virtual objects, making a more immersive experience for the user. It consists of a track pad, grip buttons and a dual-stage trigger as seen in Figure 4 (VIVE, 2018). The Vive tracker functions similar to Vive controllers and the Vive headset by collecting information from the infrared emitted by base stations. By using the tracker, the user will have an immersive VR experience (VRHeads, 2018; Lang, 2017).

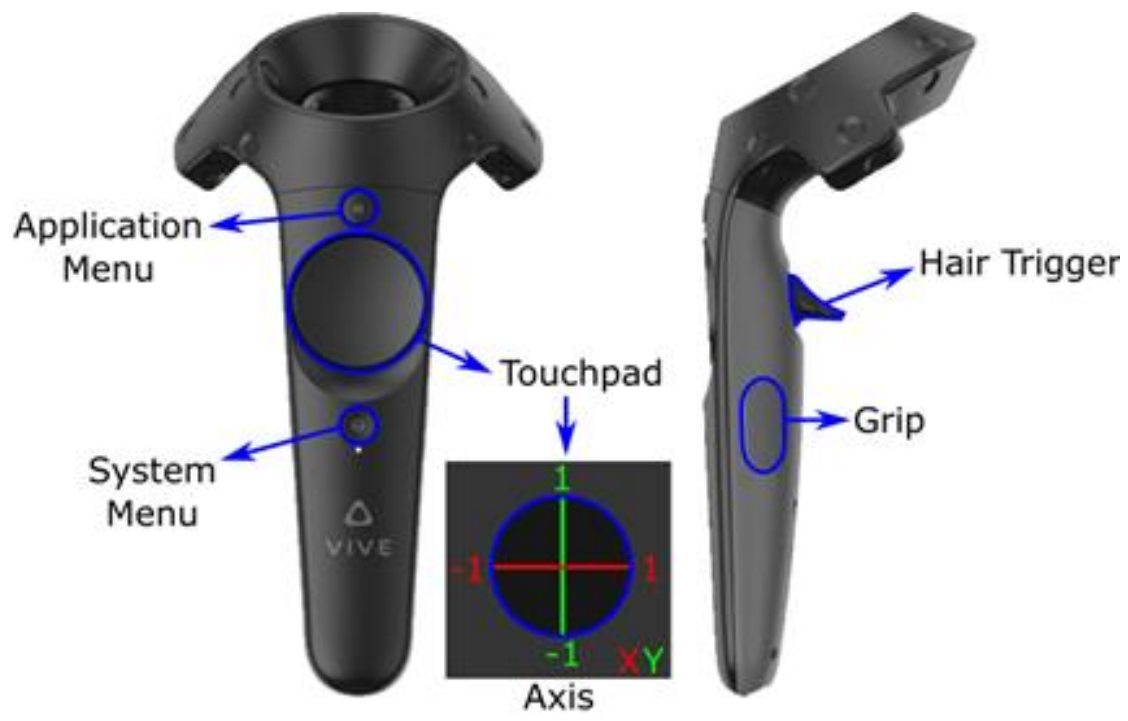

Fig. 4. HTC Vive controller buttons.

The HTC Vive base stations, also known as lighthouse-tracking system consists of two black boxes that create a 360-degree virtual space up to $15 \times 15$ foot radius (VIVE, 2018). This lighthouse tracking system tracks every moment with sub-millimeter precision with the aid of 37 sensors in the headset (VIVE, 2018). Figure 5 displays a HTC Vive base stations set up position. 


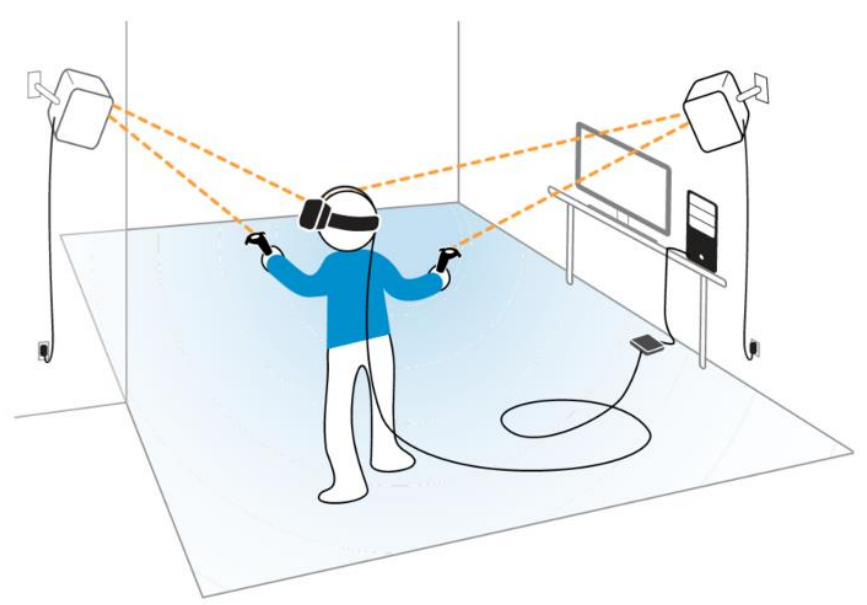

Fig. 5. HTC Vive base stations set up position.

\subsection{Challenges of VR techniques and tools}

The challenges until the recent years for VR glasses have been the medical issues related to the effects on human eyes and head. In addition, moving towards the virtual reality world have been missing proper methods. There are several commercially reasonable options are available in the market today. For instance, HTC VIVE and Oculus Rift came to the market during summer 2016. At the same time, the major game engines become compatible with the VR glasses. Of course, the main software solution for the glasses is from game industry.

Manufacturing design tools, which have been developing to support to the VR same time. The support for VR in ABB Robot Studio (http://new.abb.com/products/robotics/robotstudio) was released in summer 2017 and Visual Components software (http://www.visualcomponents.com/) usable for VR environment also have been released by ABB company (www.abb.com) at its early release for VR as well.

The more convenient way to build initial models for factory VR demos is to use the game engines like Real engine of Unity. The 3D models can be imported from the 3D design tools and the factory layout can be built using the game engines.

\subsection{Calibration of virtual space}

Once the user uses VR glasses there needs to allocate free space for short movements. User is using teleporting for longer movements to reach the devices for service needs in the virtual world. Once the user is close enough to the specific area within the free space, fine-tuning of the user's movements is done by walking. HTC VIVE uses two lighthouses (https://en.wikipedia.org/wiki/HTC_Vive) using laser technology to place the user and the remote controllers in the virtual world. The glasses are covering all the view of vision but the user can use front-facing camera that enables the user to monitor their surroundings without removing their headset (https://en.wikipedia.org/wiki/HTC_Vive).

\section{Basic requirements and Technical details of the case example}

In order to visualize the necessary repair and maintenance activities within $3 \mathrm{D}$ VR environment, a case company was selected. The application simulates a power plant in a virtual 
world, in which the users can freely move and interact with 3D objects. The engine model in the power plant was taken from the case company, a global leader in advanced technologies and complete lifecycle solutions for the marine and energy markets. The application also guides the users to do maintenance task and necessary action in disaster scenario. In this application, there are several basic requirements in order to visualize and guide the VR environment, which can be outlined as follows:

- The user can freely move around by walking for the short distance or tele- porting for the long distance movement.

- The user can interact with multiple objects by using the trigger buttons.

- The user is guided for the maintenance work which is changing the engine filter.

- The user is guided for urgent action when disaster scenario happens which is closing the valve for steam leak scenario.

- The application simulates a realistic environment for the user to blend in.

- Visual effects and animations are added to the scene.

- There are blinking exclamation mark to indicate the tasks user need to do.

- Return to default scene after pressing left hand controller menu button.

- Engine room scene: A minimap in top view style attached to right hand by pressing right hand controller menu button.

- Control room scene: A screen to view and control the interface of Internet of Things (IoT) system.

- Control room scene: A virtual keyboard to fill in the username and password for the IoT screen.

Based on the above mentioned requirements, required use case diagram is presented in Figure 6. Use case diagram describes a set of user actions with the system. Figure 6 displays the relationship between the external users with the functions of the system. Although some application functions are available in every scene such as user movement and user interaction with objects, the others are categorized into three scenes: the default scene, the control room scene and the engine room scene. 


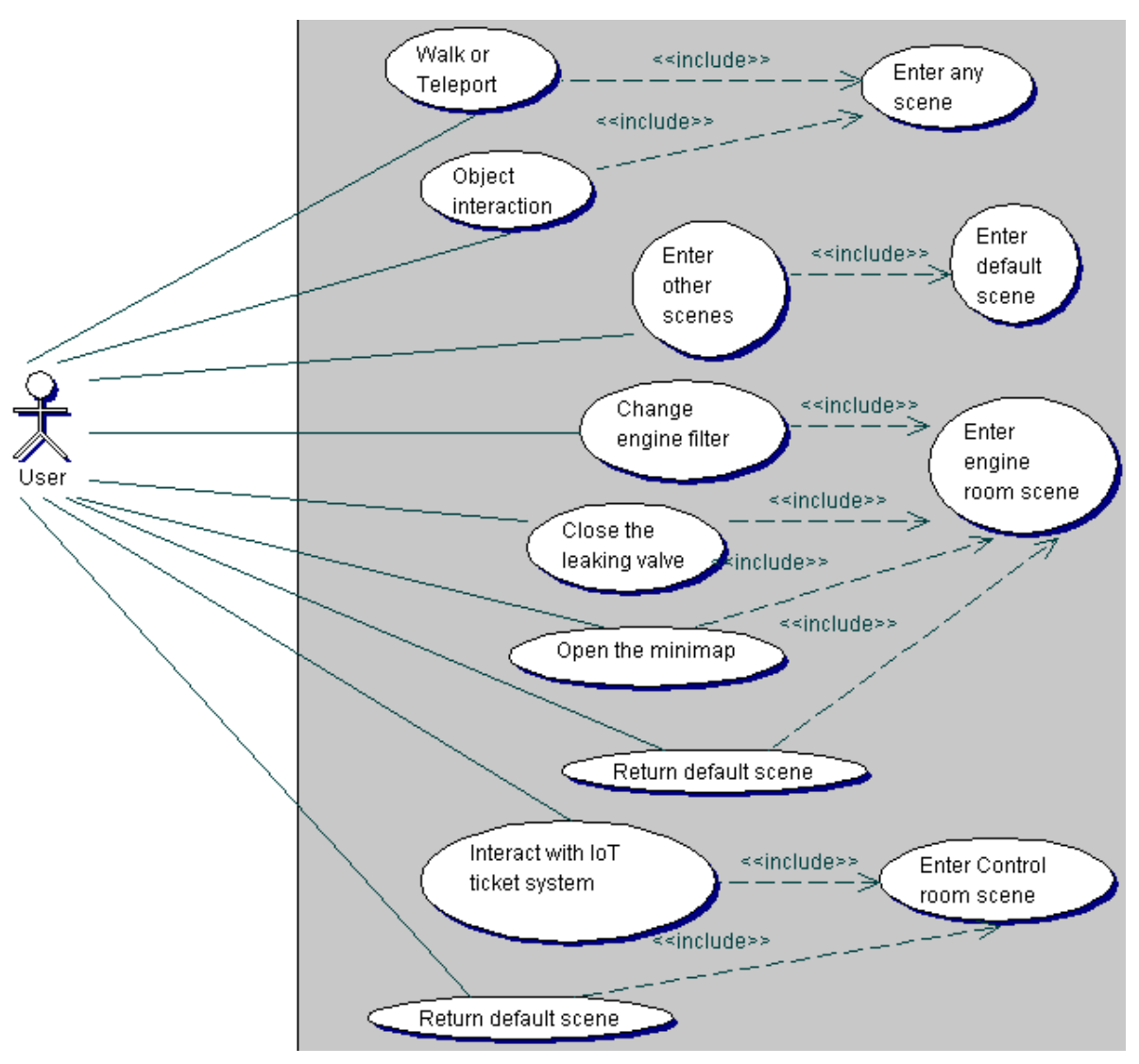

Fig. 6. Application use case diagram.

The default scene is where the user will be located in after starting the application. The main function of this scene is to let users be familiar with the environment and to know how the controller works, how they can move by walking or teleporting, how they can interact with 3D objects. The scene also includes three big screens with running video for exhibition purpose and a power plant miniature. From this default scene, user can choose to enter other scenes. The control room scene imitates an operation control center, where the whole power plant facility can be monitored or controlled. In this room, there is a warning screen with notifications about maintenance works or actions to be done in case of emergency. The user can control the IoT system by using the right controller to interact with the touch screen. The menu button of the left controller is used to relocate the user to the default scene. The engine room scene simulates the power plant establishment. This scene includes all fundamental features of the applications such as engine models, maintenance work and emergency case. A mini map attached to user's right hand can be toggle on/off by the menu button of the right controller. The menu button of the left controller is still used to switch to the default scene.

\subsection{Terminology related to virtual reality environment}

(a) Virtual reality template

Unreal Engine 4.13 introduced the official Virtual Reality template made entirely in Blueprint. This VR template is targeting desktop and console only and it supports Oculus Rift, 
HTC Vive and PlayStation VR out of the box. This template is considered as the fastest method to start a VR project.

\section{(b) Motion controller teleportation}

Motion controller teleportation feature is included in Virtual Reality template. After pressing the touchpad of the controllers, a blue circle will appear to indicate the position that the user will be moved to. The moment the touchpad is released, this circle will disappear and the user will be located at a new location. Figure 7(a) demonstrates how the blue circle looks like.

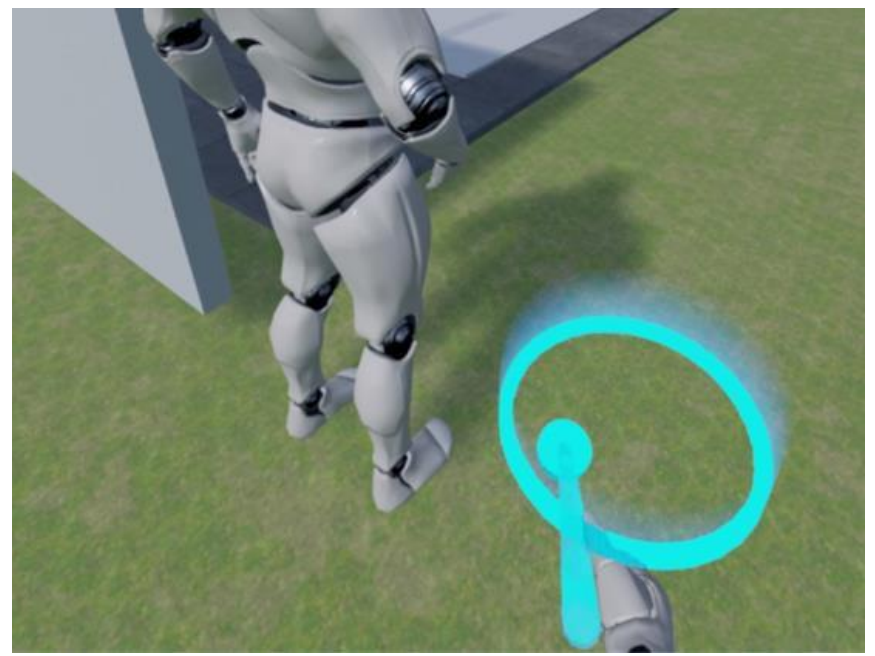

(a)

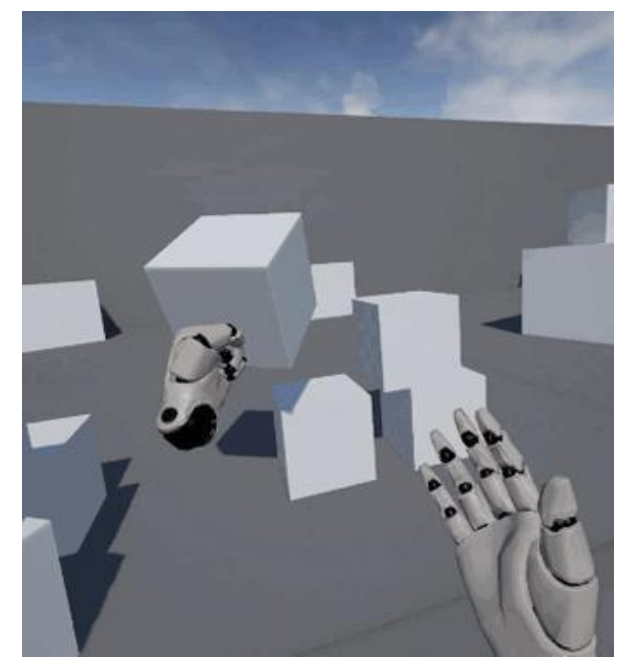

(b)

Fig. 7. (a) Teleporting Circle Indicator (b) Objects interaction.

(c) Object integration

In the VR template, there are multiple objects which are instances of blueprint. By using the trigger button of the controllers, user can grab and move these cubes [Figure 7(b)]. These objects were made to help the developers understand how to implement interactable objects.

(d) Default map

The default map is used to demonstrate the implementation of one example display screen in the default scene. Figure 8(a) demonstrates how it looks like in gameplay. 


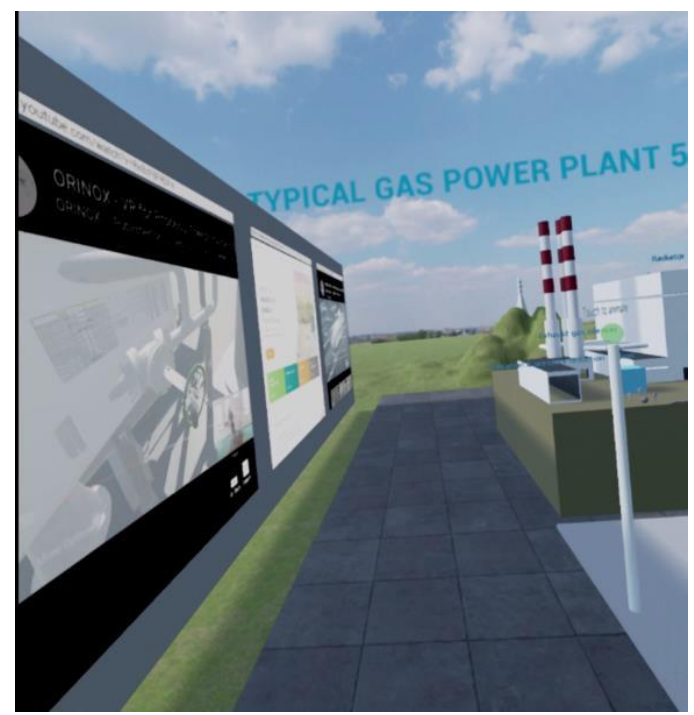

(a)

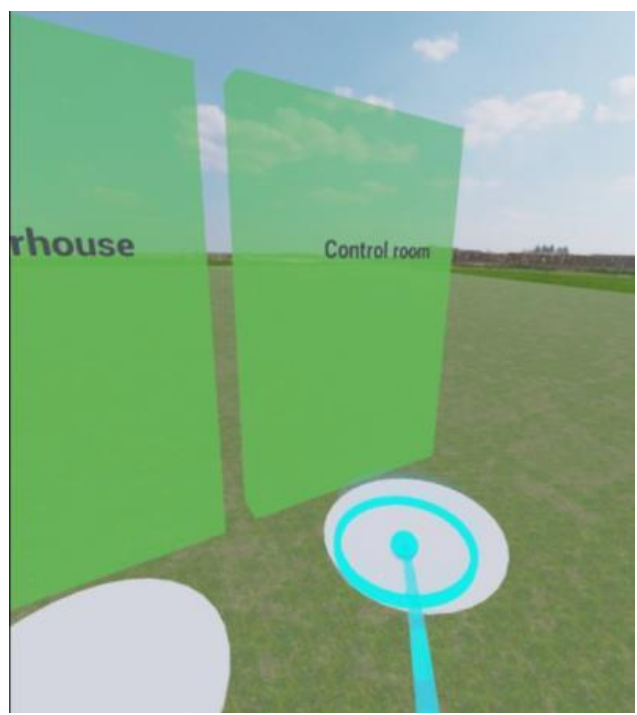

(b)

Fig. 8. (a) Showcase Screens gameplay (b) Two scene changing doors gameplay.

(e) Scene changing doors

The default scene provides two scene changing doors to allow the user to enter other scenes. The powerhouse door is for the engine room scene and the other is for the control room scene [Figure 8(b)]. Each of these doors was implemented so that the user can enter other scene by pressing the trigger buttons of the controllers while touching corresponding door

(f) Control room map

There are multiple warning screens in the control room which notifies the user what need to be done. An example is shown in Figure 9(a).

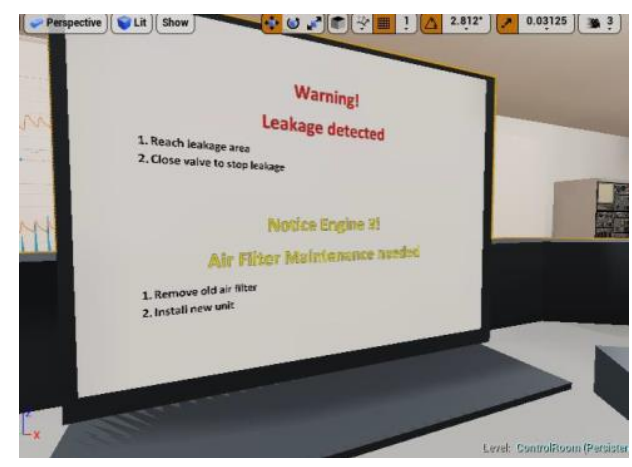

(a)

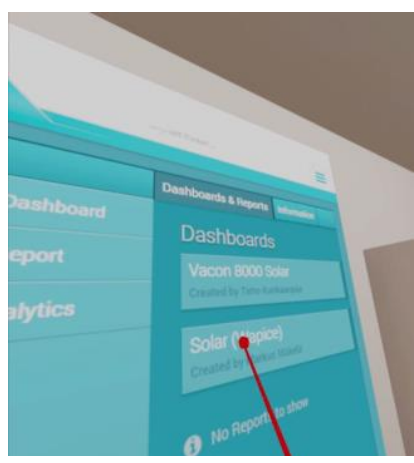

(b)

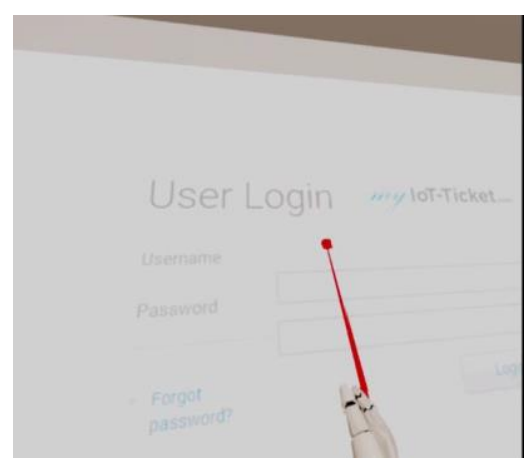

(c)

Fig. 9. (a) Warning Screen gameplay (b) IoT screen gameplay (c) First time user authentication.

(g) IoT ticket screen

The IoT Ticket Screen is served as a touch screen, which enables the user to interact with this 
system. The right controller emits a laser light to notify the interaction point [Figure 9(b)]. The trigger button can be used to click, drag or drop as the mouse pointer works on any browser.

(h) Virtual keyboard

The IoT ticket system requires authentication for the first time user so a virtual keyboard is needed for the user to set their username and password. Figure 9(c) displays the user login as the first time user authentication.

(i) Engine room map: steam effect

In order to make the scene be more realistic, the steam effect was added. This effect appears at the exhale valve of the engine, the power plant silos and the container area required user interaction. Figure 10 demonstrates how the steam effect looks like in gameplay.
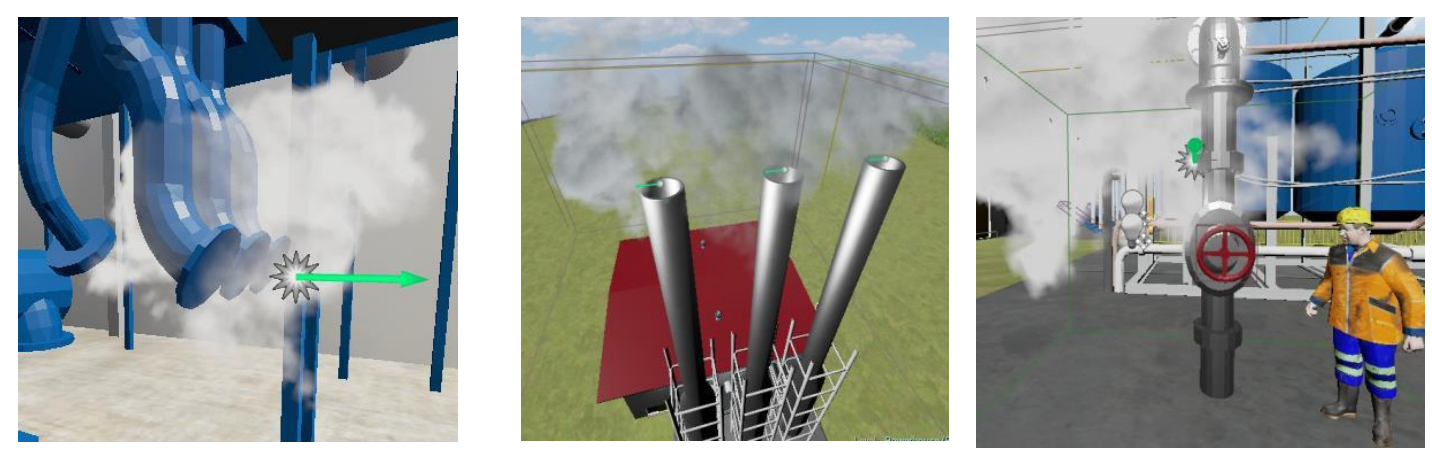

Fig. 10. Steam effect gameplay.

(j) Blinking exclamation mark

There are two blinking exclamation marks along with the worker model in the scene to get users attention for the maintenance work and the emergency case as in Figure 11 . These blinking marks will disappear if the user comes near to the place because their intention has been achieved. 

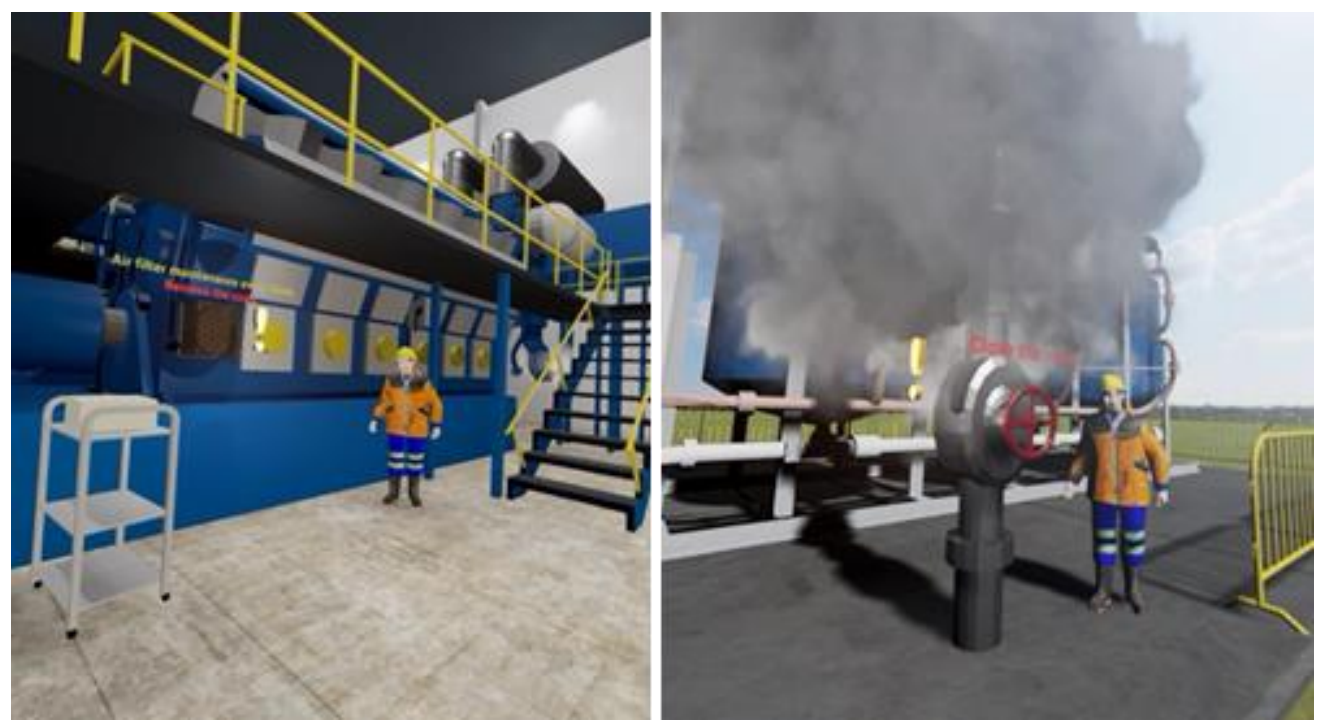

Fig. 11. Blinking mark and worker model for user attention.

\section{(k) Door interaction}

There are two doors in the scene which let the user use the motion controllers to open them. Figure 12 describes the door opening procedure to go outside of the engine building. The door is closed by default when the user enters the scene. An instruction will be displayed when the user comes near to the door. By using the trigger buttons of the controllers, user can make the door open to go outside.
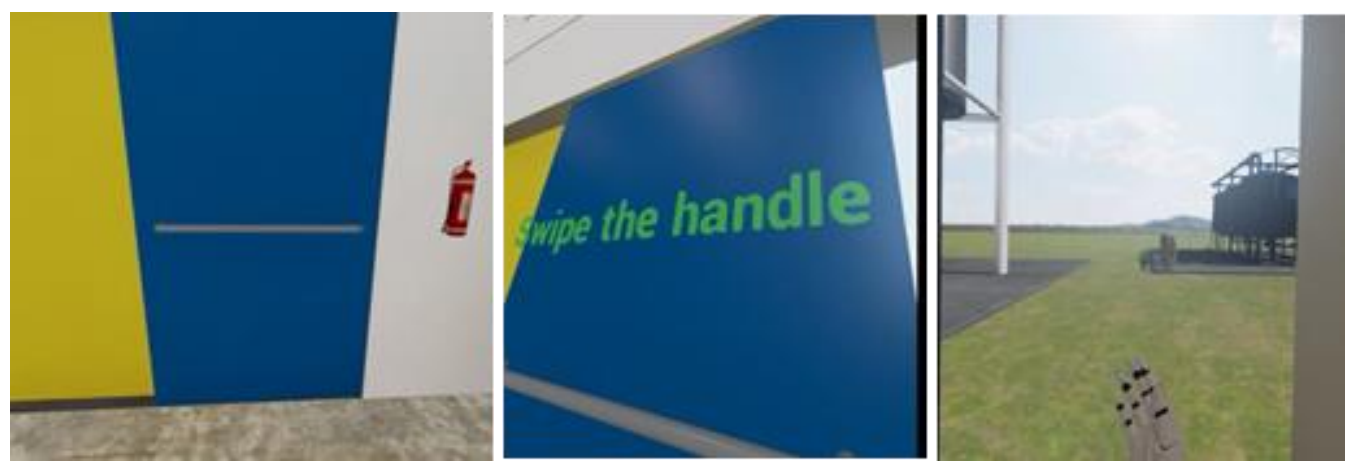

Fig. 12. Opening door procedure gameplay.

(1) Mini-map

The engine room scene has a feature called a mini-map, which enables the users to track their real-time character location. The mini-map shows the top view of the scene and mark user location with a green blinking dot. Figure 13 describes how the mini-map looks like when running the application. 

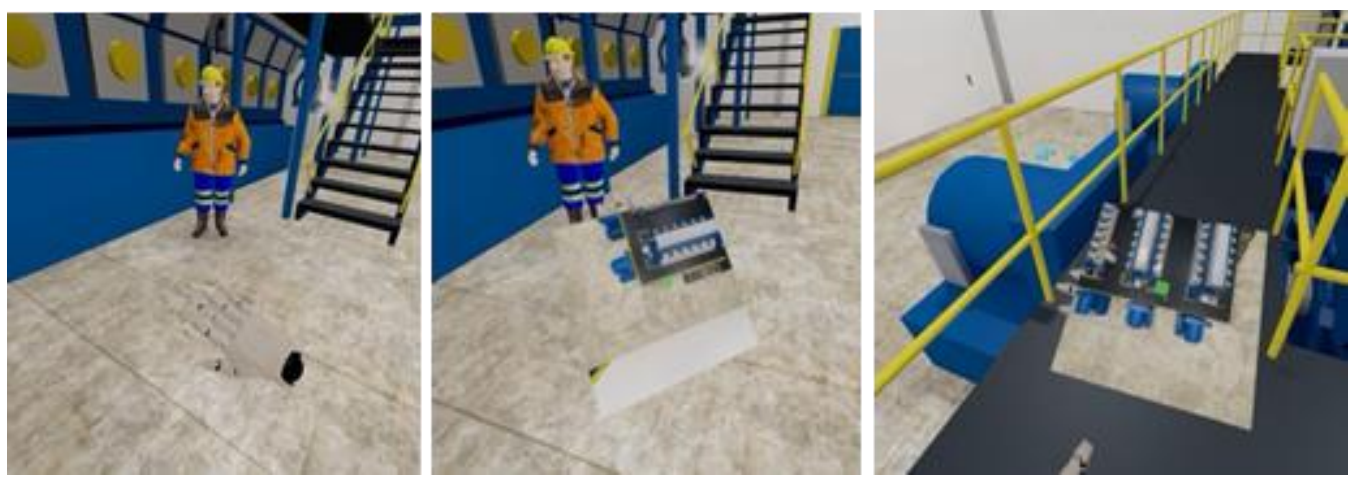

Fig. 13. Mini-map gameplay.

\section{Virtual reality for industrial maintenance: a case study}

With the objective to demonstrate the application of virtual reality in industrial operations and maintenance, a case example is presented in this section. This demonstration offers an exclusive guideline to operation and maintenance of a case company's product. The case company is engaged in global energy business and its product is power generation engine, which can be operated by either diesel or gas as fuel.

This demonstration is especially orchestrated to present the step by step methodology to perform virtual operational maintenance within the case company's product. Figure 14 (a, b, c) highlights the maintenance engineer with VR control, virtual control room (where necessary maintenance works are scheduled on a dashboard), and display of faults respectively. Any operational abnormalities are displayed over the dashboard as seen in Figure 14(c). From Figure 14(c), it is seen that there displays a warning notice on leakage detection and air filter maintenance needed. The dashboard works as the base of monitoring all the status update of each workable process in the case company. Both the maintenance works are controlled and managed virtually.

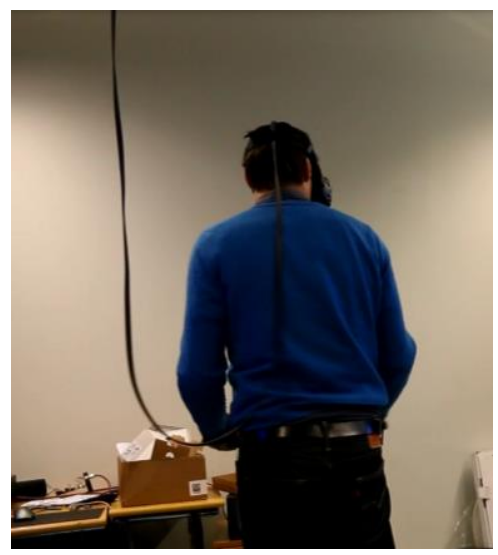

(a) Virtual maintenance by an engineer

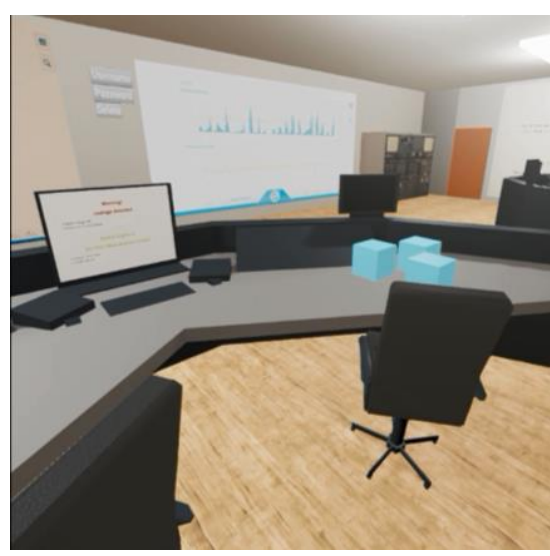

(b) Virtual maintenance dashboard

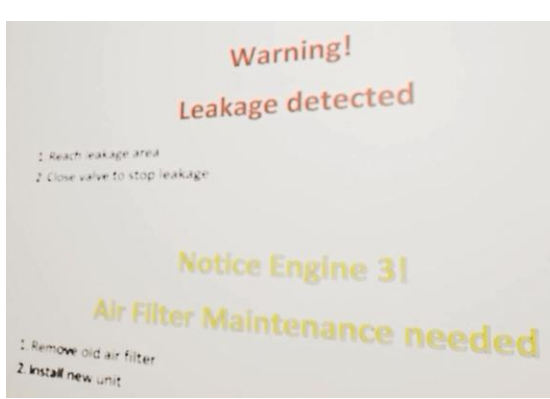

(c) Display of faults summary

Fig. 14. Demonstration of virtual reality in industrial maintenance work. 
The necessary maintenance work at the engine room associated with the detection of leakage is displayed in Figure 15 (a, b, c). From Figure 15 (b) it is seen that the detected leakage was controlled virtually by closing the valve. Figure 15 (c) also notified that the necessary maintenance task to close the valve is completed. Both the status updates are displayed over the virtual dashboard accordingly.

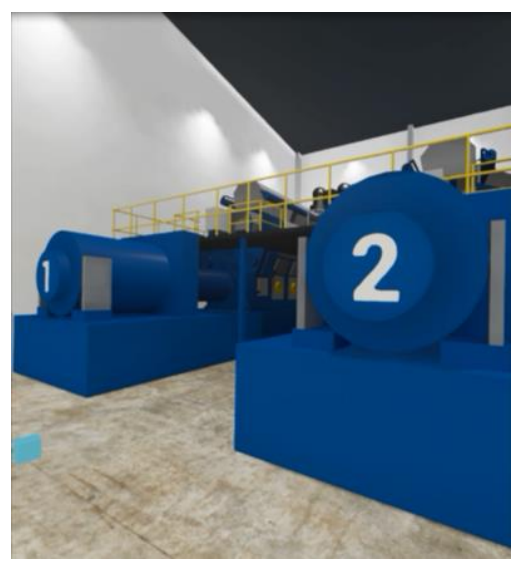

(a) Display of engine room

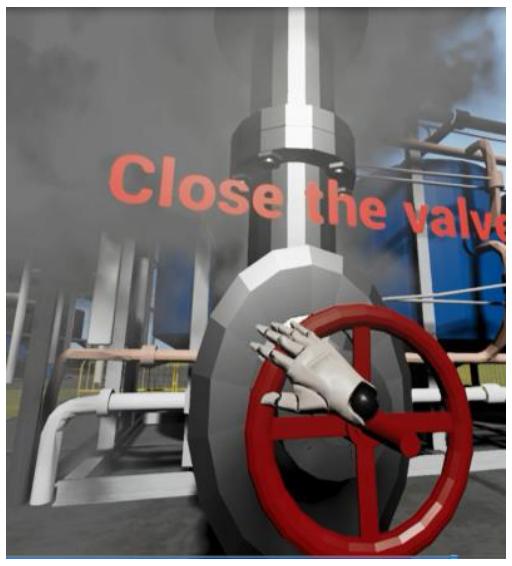

(b) Display to close the valve

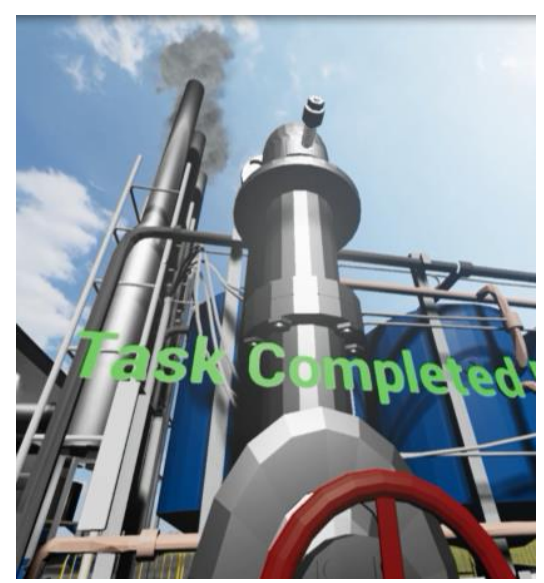

(c) Display of task completion

Fig. 15. Demonstration of virtual reality in industrial maintenance work.

Second maintenance task related to maintaining the air filter is displayed in Figure 16 (a, b, c). This maintenance task is accompanied by displaying the required command or guideline. For instance, Figure 16 (a) displays the command to 'remove the cover', which is necessary before removing the dirty filter. Figure 16 (b) displays the command 'remove dirty filter', while Figure 16(c) shows the command on 'install new filter.

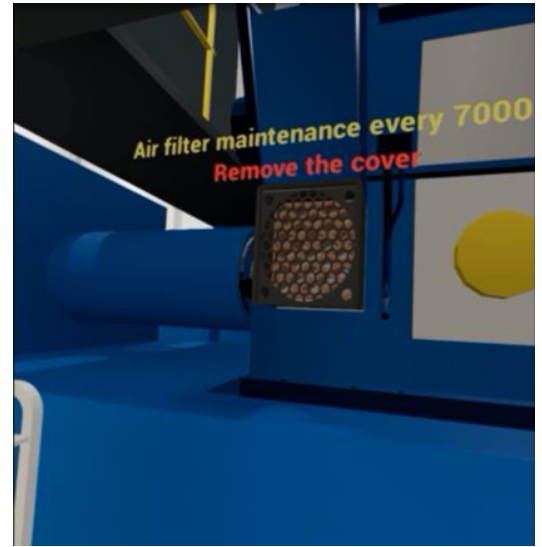

(a) Display of cover removal

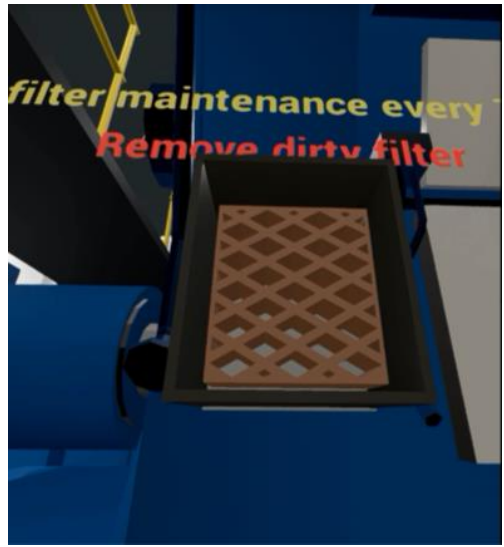

(b) Display of filter removal

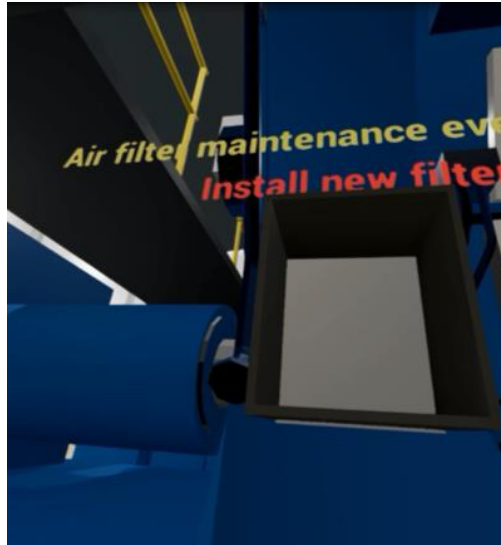

(c) Display of filter installation

Fig. 16. Demonstration of virtual reality in industrial maintenance work. 
When the dirty filter is removed as shown in Figure 16(c), a new filter is replaced as displayed in Figure 17(a). After properly installed the new filter, it is necessary to put back the filter cover as shown in Figure 17(b). After completing the installation process the task is considered as completed as dispalyed in Figure 17(c).

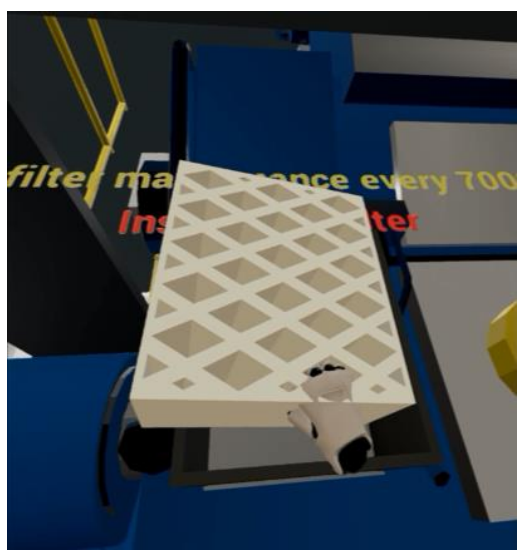

(a) Display of new filter
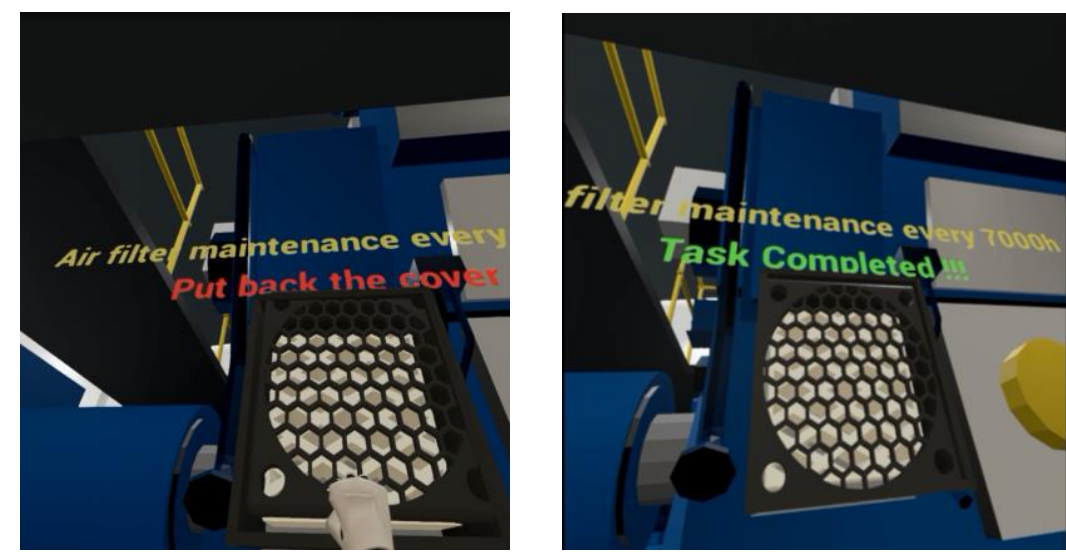

(b) Display of put back the cover (c) Display of task completion

Fig. 17. Demonstration of virtual reality in industrial maintenance work.

This complete case demonstration shows the importance of virtual maintenance to the manufacturing and maintenance engineers. It provides the step by step guidelines to required maintenance work virtually. This virtual maintenance work is especially important to the maintenance engineers with respect to training and learning perspectives.

\section{Empirical and managerial implications}

The repair and operational maintenance and training activities as explained and displayed in Section 8 are taken from a real life company, engaged in global energy business. The company is invested plenty of resources to improve its services to the potential customers. To ensure better customer service, the study company employs new service engineers every year, whom require necessary training. The company wishes to deploy a virtual-based facility that can be helpful to support its plan training for the newly employed service engineers. Keeping such objective in mind, this research study conducted several pilot studies to ensure VR-based training for the service engineers. The outcomes from such studies show that VR-based training would be effective and beneficial for the company with respect to cost and time. This VR-enable training model will ensure efficient initial training and experience before conducting the costly real-life experiments. This way it saves costly resources and ensures operational safety and enhanced confidence and reliability to every day's service works. Table 2 visualizes the fundamental differences between traditional versus VR-based training and maintenance in industries.

\section{Table 2}

Comparison of performances between traditional and VR-based training and maintenance activities. 


\begin{tabular}{|c|c|c|}
\hline KPI/Criteria & $\begin{array}{l}\text { Traditional training and } \\
\text { maintenance }\end{array}$ & VR-based training and maintenance \\
\hline Training facility & $\begin{array}{l}\text { Required expensive } \\
\text { equipment/resources to conduct } \\
\text { necessary training and maintenance }\end{array}$ & $\begin{array}{l}\text { Required } \\
\text { equipment/resources to conduct } \\
\text { training and maintenance due to } \\
\text { simulation-based environment }\end{array}$ \\
\hline $\begin{array}{l}\text { Flexibility/change } \\
\text { management }\end{array}$ & $\begin{array}{l}\text { Higher cost to change and test any } \\
\text { layout/equipment }\end{array}$ & $\begin{array}{l}\text { Lower cost to change and test any } \\
\text { layout/equipment due to availability } \\
\text { of VR-based environment }\end{array}$ \\
\hline Traini & $\begin{array}{l}\text { Training cannot be conducted until } \\
\text { and unless the real-life } \\
\text { factory/equipment is installed }\end{array}$ & $\begin{array}{l}\text { Training can be conducted as soon } \\
\text { as the VR-based environment of the } \\
\text { factory/equipment is installed }\end{array}$ \\
\hline $\begin{array}{l}\text { Online- training } \\
\text { facility }\end{array}$ & Online training is not possible & Online training is easily possible \\
\hline Lead-time & $\begin{array}{l}\text { Longer time is necessary to offer } \\
\text { maintenance training of the } \\
\text { personnel }\end{array}$ & $\begin{array}{l}\text { Competitively faster time is } \\
\text { necessary to offer maintenance } \\
\text { training of the personnel }\end{array}$ \\
\hline Use of resource & $\begin{array}{l}\text { Expensive human resource is } \\
\text { required for the training and } \\
\text { maintenance activities }\end{array}$ & $\begin{array}{l}\text { Comparatively low cost computer- } \\
\text { generated } 3 \mathrm{D} \text { human model is used } \\
\text { for the training and maintenance } \\
\text { activities }\end{array}$ \\
\hline $\begin{array}{l}\text { Mainte } \\
\text { enviro }\end{array}$ & $\begin{array}{l}\text { Offer costly real-life maintenance } \\
\text { environment }\end{array}$ & $\begin{array}{l}\text { Offer low cost computer simulation } \\
\text { based maintenance environment }\end{array}$ \\
\hline $\begin{array}{l}\text { Communication } \\
\text { pattern }\end{array}$ & $\begin{array}{l}\text { Less communication between } \\
\text { designers and maintenance } \\
\text { engineers }\end{array}$ & $\begin{array}{l}\text { Ensure higher communication } \\
\text { between designers and maintenance } \\
\text { engineers }\end{array}$ \\
\hline $\begin{array}{l}\text { Performance } \\
\text { evaluation }\end{array}$ & $\begin{array}{l}\text { Slow and lower performance to } \\
\text { training and maintenance work }\end{array}$ & $\begin{array}{l}\text { Faster and comparatively higher } \\
\text { performance to training and } \\
\text { maintenance work }\end{array}$ \\
\hline $\begin{array}{l}\text { Maintenance } \\
\text { safety }\end{array}$ & $\begin{array}{l}\text { Lower safety level due to real-life } \\
\text { maintenance work }\end{array}$ & $\begin{array}{l}\text { Comparatively higher safety level } \\
\text { due to virtual environment }\end{array}$ \\
\hline
\end{tabular}

The novel virtual maintenance application for industrial operations and safety provides recommendations on maintenance safety during the early stages of product design. The virtual reality approach contributes to combine static and dynamic check to figure out design flaws and detects the potential defects via virtual maintenance technology and provides safety evaluation of product design and development.

The intuitive and immersive human-computer interface through virtual reality can be an efficient tool for maintenance training. Such virtual reality application for maintenance training is orchestrated in a virtual workshop environment. This virtual workshop environment shows the potential of desktop virtual reality to provide necessary maintenance training with reduced cost (Gavish et al., 2015).

The industrial operations and maintenance is a complex system consisting of several interrelated human and machine components. Intensive education and training has been identified 
as the primary intervention strategy to improve the quality and reliability on the industrial inspection process. In order to be successful in proper training, it is critical to provide inspectors with appropriate tools and environment. In such circumstance, the implementation of virtual reality system to industrial inspection and training can be added value.

Although, it is useful to apply virtual reality in industrial training and maintenance, however, the virtual reality interfaces are difficult and expensive to build. It requires computer graphics community in order to be able to get benefit from virtual reality application in maintenance work. To address such important issue, it is required to measure the degree of immersion and presence of virtual environment simulator. This virtual environment conducts visual inspection task that affects the quality of task performance. It is proved that the result from virtual reality training system is better and preferred over the PC-based training tool (Vora, 2002).

\section{Conclusions and future research directions}

The virtual reality platform, which is an integral part of digital factory concept for industrial maintenance tasks is complex activities that require specific knowledge and procedure. This research study developed a digital factory model in virtual reality environment and test the capacity of virtual training and maintenance of industrial systems. As in industrial environments there are variety of machines are in use, industrial firms find themselves difficulties in operations and maintenance. Such maintenance works are also complicated, risky and expensive as well. Therefore, it would be a good idea for the industrial firms to finding ways to more efficiently train engineers to perform maintenance tasks.

In such circumstances, application of digital factory platform can offer promise of making industrial maintenance and training better and more efficient. The digital factory offers virtual maintenance system, which is worked within a computer-generated environment with necessary simulation process to interact with the real system. To enable such environment efficiently, there needs to integrate different technologies with the virtual reality system to allow the users to interact with the virtual scenario in a multi-sensory manner.

The main objective of this research study was to develop a virtual environment simulating the maintenance operations of a case company. This application provides the user virtual industrial operations and maintenance work. The study has achieved its main objective. During the application phase of the development process, many implementation approaches have been considered and tested in order to choose the most suitable one for optimization and performance purpose. The application has been tested multiple times and was running smoothly and stably.

The main challenges in the development process were to get familiar with virtual reality environment within digital factory platform and to acquire required knowledge of 3D computer graphics. It also took a large amount of time to find and put the 3D object models into use. Developing the application has provided an opportunity to learn new technologies. There were many problems and difficulties during the implementation but all of them have been overcome in the end. The application has a good potential for further development. Many other industrial operations can be added to the scene, the case company's product (power plant engine) can be updated to new model and the virtual environment can still be modified in order to be more realistic.

The research works that are provided in this paper supports the virtual maintenance nicely. A case example is demonstrated to visualize the step-by-step maintenance work by virtual reality. The case demonstration enables to illustrate the relevant maintenance works, which can be helpful 
for the engineer $\backslash$ technician to acquire sufficient knowledge and expertise before conducting the real-life maintenance works.

This research work was mostly concentrated to apply the virtual reality technique in industrial maintenance without considering the accompanied cost analysis. The future work will be concentrated to analyze the financial contents between the virtual maintenance with real-life maintenance task. In addition, the effectiveness between the virtual maintenance works with reallife one will also be compared with respect to duration, performance and quality as well.

\section{References}

Akiyoshi, M., Miwa, S., Ueda, T., \& Nishida, S. (1995). A learning environment for maintenance of power equipment using virtual reality. Proceedings of Fifth International Conference on Image Processing and its Applications, Edinburgh, UK, 1995, pp. B5/1-B5/6.

Alamri, A., Eid, M., Iglesias, R., Shirmohammadi, S., \& El Saddik, A. (2008). Haptic virtual rehabilitation exercises for poststroke diagnosis. IEEE Transactions on Instrumentation and Measurement, 57, 1876-1884.

Amir, P., Amer, E. and Eric R.P. F. (2017). The application of Augmented Reality and Virtual Reality in the construction industry using wearable devices In: The 9th International Conference on Construction in the 21st Century (CITC-9), Dubai, United Arab Emirates, March 5-7.

Bohil, C., Alicea, B., \& Biocca, F.A. (2011). Virtual reality in neuroscience research and therapy. Nature Reviews Neuroscience, 12, 752-762.

Brun, A., \& Zorzini, M. (2009). Evaluation of product customization strategies through modularization and postponement. International Journal of Production Economics, 120(1), 205-220.

Bruno, F., Bruno, S., De Sensi, G., Luchi, M-L., Mancuso, S., \& Muzzupappa, M. (2010). From $3 \mathrm{D}$ reconstruction to virtual reality: A complete methodology for digital archaeological exhibition. Journal of Cultural Heritage, 5(4), 42-49.

Bryson S. (1994). Virtual Environments in Scientific Visualization, Proceedings of ACM VRST 94.

Buriol, T. M., Rozendo, M., de Geus, K., Scheer, S., \& Felsky, C. (2009). A virtual reality training system for live line maintenance of power distribution networks. Conference ICBL2009, Florianopolis, Brazil.

Canetta, L., Redaelli, C., \& Flores, M. (2011). Digital Factory for Human-oriented Production Systems. The Integration of International Research Projects, 1st ed. London: Springer.

Chen, C-Y. (2016). Cognitive support for learning computer-based tasks using animated demonstration. Interactive Learning Environments, 24(4), 859-874.

Cheng, K., \& Bateman, R.J. (2008). E-manufacturing: characteristics, applications and potentials. Progress in Natural Science, 18(11), 1323-1328.

Chi, H-L., Kang, S-C., \& Wang, X. (2014). Research trends and opportunities of augmented reality applications in architecture, engineering, and construction. Automation in Construction, 33, 116-122.

Choi, S., Jung, K., \& Noh, S.D. (2015). Virtual reality applications in manufacturing industries: past research, present findings, and future directions. Concurrent Engineering Research and Applications, 23(1), 40-63. 
Chryssolouris, G., Mavrikios, D., Papakostas, N., Mourtzis, D., Michalos, G. and K Georgoulias, K. (2009). Digital manufacturing: History, perspectives, and outlook. Proceedings of the Institution of Mechanical Engineers, Part B: Journal of Engineering Manufacture, 223(5), 451-462.

De Marchi, V., Di Maria, E., \& Micelli, S. (2013). Environmental strategies, upgrading and competitive advantage in global value chains. Business Strategy and the Environment, 22(1), 62-72.

El-Chaar, J., Boer, C-R., Pedrazzoli, P., Mazzola, S.,\& Dal Maso, G. (2011). Interactive 3D virtual environments for industrial operation training and maintenance. Proceedings of 2011 9th International Conference on Reliability, Maintainability and Safety, 12-15 June, Guiyang, China

Frampton, R. (1995). VR: Multimedia and more - the role of virtual reality in the commercial and industrial society. Proceedings of International Conference on Virtual Systems and Multimedia'95 (VSMM'95), Gifu, Japan, 225-229.

Freeman, D., Reeve, S., Robinson, A., Ehlers, A., Clark, D. Spanlang, B., \& Slater, M. (2017). Virtual reality in the assessment, understanding, and treatment of mental health disorders. Psychological Medicine, 47(14), 2392-2400.

Galambos, P., Csapó, A., Zentay, P., Fülöp, I.M., Haidegger, T., Baranyi, P., \& Rudas, I.J. (2015). Design, programming and orchestration of heterogeneous manufacturing systems through VRpowered remote collaboration. Robotics and Computer-Integrated Manufacturing, 33, 68-77.

Gamito, P., Oliveira, J. Coelho,C., Morais, D., Lopes, P., Pacheco, J., Brito, R., Soares, F., Santos, N., \& Barata, A.F. ( 2017). Cognitive training on stroke patients via virtual reality-based serious games. Disability and Rehabilitation 39(4), 385-388.

Ganier, F., Hoareau, C., \& Tisseau. J. (2014). Evaluation of procedural learning transfer from a virtual environment to a real situation: a case study on tank maintenance training. Ergonomics, 57(6), 828-843.

Gavish, N., Gutiérrez, T., Webel, S., Rodríguez, J., Peveri, M., Bockholt, U., \& Tecchia, F. (2012). Evaluating virtual reality and augmented reality training for industrial maintenance and assembly tasks. Interactive Learning Environments, 23(6), 778-798.

Gavish, N., Gutiérrez, T., Webel, S., Rodríguez, J., Peveri, M., Bockholt, U., \& Tecchia, F. (2015). Evaluating virtual reality and augmented reality training for industrial maintenance and assembly tasks. Interactive Learning Environments, 23(6), 778-798.

Gibson A., O'Rawe M. (2018) Virtual Reality as a Travel Promotional Tool: Insights from a Consumer Travel Fair. In: Jung T., tom Dieck M. (eds) Augmented Reality and Virtual Reality. Progress in IS. Springer, Cham, pp. 93-107.

Gomes de Sa, A., \& Zachmann, G. (1999). Virtual reality as a tool for verification of assembly and maintenance processes. Computers \& Graphics, 23(3), 389-403.

Górski, F., Buń, P., Wichniarek, R., Zawadzki, P. and Hamrol, A. (2015), "Immersive city bus configuration system for marketing and sales education", Procedia Computer Science. Vol. 75, pp. 137-146.

Gosselin, F., Ferlay, F., Bouchigny, S., Mégard, C., \& Taha, F. (2010). Design of a multimodal VR platform for the training of surgery skills. In: A. M. L. Kappers (Ed.), Haptics: Generating and perceiving tangible sensations, Part II, Proceedings of the International Conference EuroHaptics 2010, LNCS 6192 (109-116), Amsterdam, The Netherlands. Berlin: Springer Berlin Heidelberg. 
Guo, Z., Zhou, D., Chen, J., Geng, J., Lv, C., \& Zeng, S. (2018). Using virtual reality to support the product's maintainability design: Immersive maintainability verification and evaluation system. Computers in Industry, 101, 41-50 (In press).

Goulding, J., Nadim, W., Petridis, P., \& Alshawi, M. (2012). Construction industry offsite production: A virtual reality interactive training environment prototype. Advanced Engineering Informatics, 26(1), 103-116.

Guttentag, D.A. (2010). Virtual reality: applications and implications for tourism. Tourism Management. 31(5), 637-651.

Gutierrez, T., Gavish, N., Webel, S., Rodriguez, J., \& Tecchia, F. (2012). Training platforms for industrial maintenance and assembly. In: Bergamasco, M., Bardy, B.G. and Gopher, D. (Eds.), Skills Training in Multimodal Virtual Environments, Boca Raton: CRC Press Taylor \& Francis Group, 227-239.

Ho, N., Wong, P-M., Chua, M., \& Chui, C-K. (2018), Virtual reality training for assembly of hybrid medical devices. Multimedia Tools and Applications, 77(23), 30651-30682.

$\mathrm{Hu}, \mathrm{X}$., Su, R. and He, L. (2016), "The design and implementation of the 3D educational game based on VR headsets", 2016 International Symposium on Educational Technology (ISET), Beijing, China, 19-21 July 2016.

Kandalaft, M.R., Didehbani, N., Krawczyk, D.C. Allen, T.T., \& Chapman, S.B. (2013). Virtual Reality Social Cognition Training for Young Adults with High-Functioning Autism. Journal of Autism and Developmental Disorders, 43(1), 34-44.

Kashiwa, K., Mitani, T. Tezura, T., \& Yoshikawa, H. (1995). Development of machinemaintenance training system in virtual environment. Proceedings of Fourth IEEE International Workshop on Robot and Human Communication RO-MAN'95, Tokyo, Japan, 1995, 295-300.

Kaufmann, H., Schmalstieg, D., \& Wagner, M. (2000). Construct3D: A Virtual Reality Application for Mathematics and Geometry Education. Education and Information Technologies, 5(4), 253-276.

Kozak, J.J., Hancock, P.A., Arthur, E.J., \& Chrysler, S.T. (1993). Transfer of training from virtual reality. Ergonomics, 36(7), 777-784.

Kuhn, W. (2006). Digital factory - simulation enhancing the product and production engineering process. Proceedings of the 2006 Winter Simulation Conference, 1899-1906.

Lang, B. (2017). Latest HTC Vives are shipping with tweaked base stations, redesigned packaging - Road to VR. Road to VR, 2017, Retrieved 2017-11-21.

Lange, B., Koenig, S., Chang, C-Y., McConnell, E., Suma, E., Bolas, M., \& Rizzo, A. (2012). Designing informed game-based rehabilitation tasks leveraging advances in virtual reality. Disability and Rehabilitation, 34(22), 1863-1870.

Lawson, G., Salanitri, D., \& Waterfield, B. (2016). Future directions for the development of virtual reality within an automotive manufacturer. Applied Ergonomics, 53(Part B), 323-330.

Lecavalier, N.C., Ouellet, E., Boller, B., \& Belleville, S. (2018). Use of immersive virtual reality to assess episodic memory: A validation study in older adults. Neuropsychological Rehabilitation - An International Journal (In press).

Lee, W.B., Cheung, C.F., \& Li, J.G. (2001). Applications of virtual manufacturing in materials processing. Journal of Materials Processing Technology, 113(1-3), 416-423.

Levinson, A., Waever, B., Garside, S., McGinn, H., \& Norman, G.R. (2007). Virtual reality and brain anatomy: a randomized trial of e-learning instructional designs. Medical Education, 41(5), 495-501. 
Li, J.R., Khoo, L.P., \& Tor, S.B. (2003). Desktop virtual reality for maintenance training: an object oriented prototype system (V-REALISM). Computers in Industry, 52(2), 109-125.

Lin, R-J., Tan, K-H., \& Geng, Y. (2013). Market demand, green product innovation, and firm performance: evidence from Vietnam motorcycle industry. Journal of Cleaner Production, 40(101-107).

Llorens, R., Gil-Gomez, J-A., Alcaniz, M., Colomer, C., \& Noe, E. (2015). Improvement in balance using a virtual reality-based stepping exercise: a randomized controlled trial involving individuals with chronic stroke. Clinical Rehabilitation, 29(3), 261-268.

Lopes, P., You, S. Cheng, L-P., Marwecki, S., \& Baudisch, P. (2017). Providing Haptics to Walls \& Heavy Objects in Virtual Reality by Means of Electrical Muscle Stimulation. Proceedings of the 2017 CHI Conference on Human Factors in Computing Systems, Denver, Colorado, USA, 1471-1482.

Maeve, S., Kyla, C., Laura, M., \& Ruth L.M. (2016). Pokémon Go and augmented virtual reality games: a cautionary commentary for parents and pediatricians. Current Opinion in Pediatrics, 28(5), 673-677.

Mantovani, F., Castelnuovo, G., Gaggioli, A., \& Riva, G. (2004). Virtual Reality Training for Health-Care Professionals. CyberPsychology \& Behavior, 6(4), 389-395.

Martin-SanJose, J.-F., Juan, M.-C., Mollá, R. and Vivó, R. (2017). Advanced displays and natural user interfaces to support learning. Interactive Learning Environments, 25(1), 17-34.

McMahan, R.P., Bowman, D.A., Zielinski, D.J., \& Brady, R.B. (2012). Evaluating display fidelity and interaction fidelity in a virtual reality game. IEEE Transactions on Visualization and Computer Graphics, 18(4), 626 - 633.

Merle, A., Chandon, J-L., Roux, E., \& Alizon, F. (2010). Perceived value of the mass-customized product and mass customization experience for individual consumers. Production and Operations Management, 19(5), 503-514.

Mujber, T.S., Szecsi, T., \& Hashmi, M.S.J. (2004). Virtual reality applications in manufacturing process simulation. Journal of Materials Processing Technology, 155-156, 1834-1838.

Nicholas Ho, N., Pooi-Mun Wong, P-M., Chua, M.,\& Chui, C-K. (2018). Virtual reality training for assembly of hybrid medical devices. Multimedia Tools and Applications, 1-32 (In press).

Nomura, J., \& Sawada, K. (1999). Virtual reality technology and its industrial applications. Control Engineering Practice, 7(11), 1381-1394.

Ong, S.K., \& Nee, A.Y.C. (2004). A brief introduction of VR and AR applications in manufacturing. in: Ong, S.K. and Nee, A.Y.C. (Eds.), Virtual and Augmented Reality Applications in Manufacturing, Springer-Verlag, London, 1-11.

Pappas, M., Karabatsou, V., Mavrikios, D., \& Chryssolouris, G. (2006). Development of a webbased collaboration platform for manufacturing product and process design evaluation using virtual reality techniques. International Journal of Computer Integrated Manufacturing, 19(8), 805-814.

Parsons, S., \& Mitchell, P. (2002). The potential of virtual reality in social skills training for people with autistic spectrum disorders. Journal of Intellectual Disability Research, 46(5), 430-443.

Popovski, F., \& Nedelkovski, I. (2014). Generating 3D model in virtual reality and analyzing its performance. International Journal of Computer Science \& Information Technology (IJCSIT) 6(6), 123-128.

Purschke, F., Schulze, M., \& Zimmermann, P. (1998). Virtual reality-new methods for improving and accelerating the development process in vehicle styling and design. International Conference on Computer Graphics, 26-26 June 1998, Hannover, Germany. 
Ribaupierre, S.D., Kapralos, B., Haji, F., Stroulia, E., Dubrowski, A. and Eagleson, R. (2014), "Healthcare training enhancement through virtual reality and serious games", Virtual Augmented Reality and Serious Games for Healthcare 1, Vol. 68, pp. 9-27.

Rizzo, A.A., Schultheis, M., Kerns, K.A. \& Mateer, C. (2004). Analysis of assets for virtual reality applications in neuropsychology. Neuropsychological Rehabilitation - An International Journal, Vol. 14, No. 1-2, pp. 207-239.

Rizzo, A.K., \& Kim, G.J. (2005). A SWOT Analysis of the Field of Virtual Reality Rehabilitation and Therapy. Presence: Teleoperators and Virtual Environments, 14(2), 119-146.

Sacco, M., Maso, G.D., Milella, F., Pedrazzoli, P., Rovere, D., \& Terkaj, W. (2011). Virtual Factory Manager. In: Shumaker, R. (Eds.), Virtual and Mixed Reality - Systems and Applications, London: Springer, 397-406.

Sacco M., Redaelli C., Constantinescu C., Lawson G., D’Cruz M. and Pappas M. (2007). DiFac: digital factory for human oriented production system. HCI - Human Computer Interaction conference, Beijing (PRC), 25-27 July.

Sampaio, A.Z., \& Martins, O.P. (2000). The application of virtual reality technology in the construction of bridge: The cantilever and incremental launching methods. Automation in Construction, 37, 58-67.

Schultheis, M.T., \& Rizzo, A.A. (2001). The application of virtual reality technology in rehabilitation. Rehabilitation Psychology, 46(3), 296-311.

Seth, A., Vance, J.M., \& Oliver, J.H. (2011). Virtual reality for assembly methods prototyping: a review. Virtual Reality, March 2011, 15(1), 5-20.

Shridhar, J.M., \& Ravi, S. (2002). Virtual manufacturing: an important aspect of collaborative product commerce. Journal of Advanced Manufacturing Systems, 1(1), 113-119.

Souza, C.F.M., Sacco, M. and Vieira Porto, A.J. (2006). Virtual manufacturing as a way for the Factory of the Future. Journal of Intelligent Manufacturing, 17(6), 725-735.

Standen, P.J., \& Brown, D.J. (2005). Virtual Reality in the Rehabilitation of People with Intellectual Disabilities: Review. CyberPsychology \& Behavior, 8(3), 272-282.

Stanney, K.M., Mourant, R.R., \& Kennedy, R.S. (1998). Human Factors Issues in Virtual Environments: A Review of the Literature. Presence: Teleoperators and Virtual Environments, 7(4), 327-351.

Stone, R. (2001). Virtual reality for interactive training: an industrial practitioner's viewpoint. International Journal of Human-Computer Studies, 55(4), 699-711.

Stork, A., Sevilmis, N., Weber, D., Gorecky, D., Stahl, C., Loskyll, M., \& Michel, F. (2012). Enabling virtual assembly training in and beyond the automotive industry. 18th International Conference on Virtual Systems and Multimedia (VSMM), 2-5 September 2012, Milan, Italy.

Tolio, T., Sacco, M., Terkaj, W., \& Urgo, M. (2013). Virtual factory: an integrated framework for manufacturing systems design and analysis. Procedia CIRP, 7, 25-30.

Tsai, H-C., \& Hsiao, S-W . (2004). Evaluation of alternatives for product customization using fuzzy logic. Information Sciences, 158, 233-262.

Tussyadiah, I.P., Wang, D., Jung, T.H., \& Dieck, M.C. (2018). Virtual reality, presence, and attitude change: Empirical evidence from tourism. Tourism Management, 66, 140-154 (In press).

VIVETM (2018). "VIVE virtual reality system," www.vive.com. Retrieved 2018-071-21.

Vora, J., Nair, S., Gramopadhye, A.K., Duchowski, A.T., Melloy, B.J., \& Kanki, B. (2002). Using virtual reality technology for aircraft visual inspection training: presence and comparison studies. Applied Ergonomics, 33(6), 559-570. 
VRHeads (2018). "Everything you need to know about the Vive Tracker," VRHeads, Retrieved 2018-07-21.

Wang, P., Wu, P., Wang, J., Chi, H-L., \& Wang, X. (2018). A Critical Review of the Use of Virtual Reality in Construction Engineering Education and Training. International Journal Environmental Research and Public Health, 15(6), 1204 (article number).

Wong, C.W.Y., Lai, K-h., \& Bernroider, E.W.N. (2015). The performance of contingencies of supply chain information integration: the roles of product and market complexity. International Journal of Production Economics, 165, 1-11.

Yang, X., Malak, R.C., Lauer, C., Weidig, C., Hagen, H., Hamann, B., Aurich, J.C., \& Kreylos, O. (2015). Manufacturing system design with virtual factory tools. International Journal of Computer Integrated Manufacturing, 28(1), 25-40.

Yuviler-Gavish, N., Krupenia, S., \& Gopher, D. (2013). Task analysis for developing maintenance and assembly virtual reality training simulators. Ergonomics in Design, 21, 12-19.

Zacvhmann, G. (1998). VR-techniques for industrial applications. in: Dai, F. (Eds.), Virtual Reality for Industrial Applications, Springer-Verlag Berlin Heidelberg, 13-38.

Zawadzki, P. and Zywicki, K. (2016), "Smart product design and production control for effective mass customization in the Industry 4.0 concept", Management and Production Engineering Review, Vol. 7, No. 3, pp. 105-112.

Zhang, M., Zhang, Z., Chang, Y., Aziz, E.S., Esche, S., \& Chassapis, C. (2018). Recent Developments in Game-Based Virtual Reality Educational Laboratories Using the Microsoft Kinect. International Journal of Emerging Technologies in Learning (iJET), 13(1), 138-159.

Zimmermann, P. (2008). Virtual reality aided design. A survey of the use of VR in automotive industry. Talaba, D. and Angelos Amditis, A. (Eds.), Product Engineering: Tools and Methods Based on Virtual Reality, Springer, Dordrecht, Netherlands, 277-296.

Zyda, M. (2005). From Visual Simulation to Virtual Reality to Games. IEEE Computer Society, September, 25-32. 